\title{
DIVERSIDADE GENÉTICA EM POPULAÇÃO NATURAL DE Eremanthus erythropappus (DC.) MacLeish COMO BASE PARA O MANEJO FLORESTAL
}

\author{
SYBELLE BARREIRA
}

\begin{abstract}
Tese apresentada à Escola Superior de Agricultura
"Luiz de Queiroz", Universidade de São Paulo, para obtenção do título de Doutor em Recursos Florestais, Opção: Conservação de Ecossistemas Florestais.
\end{abstract}

P I R A C I C A B A

Estado de São Paulo - Brasil

Abril - 2005 


\title{
DIVERSIDADE GENÉTICA EM POPULAÇÃO NATURAL DE Eremanthus erythropappus (DC.) MacLeish COMO BASE PARA O MANEJO FLORESTAL
}

\section{SYBELLE BARREIRA}

Engenheiro Florestal

Orientador: Prof. Dr. PAULO YOSHIO KAGEYAMA

\begin{abstract}
Tese apresentada à Escola Superior de Agricultura "Luiz de Queiroz", Universidade de São Paulo, para obtenção do título de Doutor Recursos Florestais, Opção: Conservação de Ecossistemas Florestais.
\end{abstract}

P I R A C I C A B A

Estado de São Paulo - Brasil

Abril - 2005 
Dados Internacionais de Catalogação na Publicação (CIP) DIVISÃO DE BIBLIOTECA E DOCUMENTAÇÃO - ESALQ/USP

\section{Barreira, Sybelle}

Diversidade genética em população natural de Eremanthus erythropappus (DC.)

MacLeish como base para o manejo florestal / Sybelle Barreira. - - Piracicaba, 2005.

$61 \mathrm{p}$.

Tese (doutorado) - - Escola Superior de Agricultura Luiz de Queiroz, 2005. Bibliografia.

1. Árvore florestal 2. Candeia 3. Diversidade genética 4. Eletroforense 5. Isoenzima 6. Manejo florestal I. Título

CDD 634.97355 


\section{“TUDO POSSO NAQUELE QUE ME FORTALECE”}

À minha MAMÃE

Ao meu PAI e meu irmão Sérgio, que ausentes não se cansam de olhar por mim.

Só em vocês encontro minha PAZ!!! 


\section{AGRADECIMENTOS}

Aos professores do Departamento de Ciências Florestais da Universidade Federal de Lavras, pela sólida formação em Engenharia Florestal que sem dúvida foi o alicerce para que eu hoje esteja aqui. Em especial à Professora Soraya Botelho, conselheira, amiga e incentivadora; e ao Professor José Roberto Scolforo, seu exemplo de ética e amor a Ciência Florestal serão sempre meus guias, meu terno agradecimento pelos conselhos e por ter especialmente acreditado em mim em mais este trabalho;

Ao Professor Paulo Yoshio Kageyama, ainda lembro-me de quando estar aqui era só um sonho. Pois bem, chego ao fim e não tenho dúvidas de que o universo conspirou. Obrigada pelo carinho, confiança, incentivo e orientação;

Ao Professor Flávio Gandara, sempre atencioso, meu agradecimento carinhoso;

Ao Professor José Luiz Stape pela oportunidade do treinamento em docência e pelos ensinamentos;

Às amigas Maria Andréia (Déia) e Elza Martins Ferraz, parece que foi ontem que cheguei, sem vocês nada seria possível. Obrigada pela ajuda, pela paciência (é uma virtude!), pela amizade que não tenho dúvidas, levarei comigo;

Ao Amigo Gelson, sempre pronto para auxiliar e fez isto no campo, meu obrigada carinhoso; à você Gabriela (Gabi) meu carinho especial pelo cuidado com meu trabalho e pela disposição em ajudar;

Á Gláucia, funcionária do Departamento de Ciências Florestais (UFLA), sua ajuda mesmo de longe foi essencial em momentos cruciais; também aos Engenheiros Florestais Fábio, Charles e Wagner, a ajuda de campo foi fundamental, vocês são muito competentes; 
Aos amigos de curso Mário Jorge, Ezér, Renatinha, obrigada pelos bons momentos do dia a dia, nas viagens, enfim pelo agradável convívio; e aos amigos de LARGEA: João, Cipó, Dodo, Nivaldo, Pera, Patrícia, Graciela, Karina e a querida Bia, com vocês aprendi muito;

Aos fiéis amigos fisicamente longe mas pertinho do coração, Rubens Koloski, Taysa, Valter, Luciana Lima, Eduardo Meireles e Juliana Dantas a força de vocês foi essencial nos piores momentos e os momentos de alegria são meu porto seguro. Valeu muito!

Ao Eduardo Farah, meu agradecimento pela disposição em me auxiliar e pela oportunidade de poder ensinar; Ao Hudson, amigo certo na hora certa .Obrigada!

Ao G8, não poderia esquecer de vocês: Eder, Farias, Tassiano, Juliano (Juju), Ana (Aninha), são tantos os momentos, as farras, os churrascos, as comemorações (às vezes de nada), as pautas que discutimos (impossível enumerar). Vocês ficarão em mim, e quando longe fisicamente me lembrarei com grande amor e saudades......

À você Carol, que em tantas vezes me acolheu, me fez sorrir, me fez ver o lado bom das coisas e pessoas e a quem eu tantas outras vezes acolhi, a fiz sorrir, te tratei como uma menininha sem me dar conta de sua fortaleza, que me ajudou muito. Todo o meu carinho e agradecimento. Você faz parte dos meus fiéis amigos;

À Karem, agradeço a cada dia a oportunidade de viver uma amizade tão sincera, franca, sem meias palavras, que ultrapassa distâncias. Sua dedicação, lealdade, carinho, são exemplos disto. Sua presença constante nos últimos 10 anos tem sido meu "colo" para os momentos de angústia. É por isto que posso dizer com todas as letras: eu te amo.

Agradeço a minha família: Mamãe, Sônia, Sylmara, Narciso, Melissa, Vinícius, Lícius, Gabriela, Gabriel, Renata, Raquel, Nilson, Arnoldo, Isabelle Alice, Camile e Rafael, vocês são minha vida e em todos estes anos tenho tido as provas de que posso contar com vocês sempre e em todo momento, é sem dúvida um amor incondicional. Agradeço o apoio e o entendimento de minha ausência para que eu pudesse realizar este sonho.....Esta vitória é de vocês. 


\section{SUMÁRIO}

RESUMO

Página

SUMMARY

1 INTRODUÇÃO.

2 REVISÃO DE LITERATURA.................................................................. 4

2.1 Caracterização da espécie................................................................................ 4

2.2 Biodiversidade e Manejo................................................................................ 6

2.3 Diversidade genética em espécies arbóreas........................................................ 7

2.4 Sistema de reprodução de espécies arbóreas tropicais...................................... 10

2.5 Manejo na diversidade genética de espécies arbóreas...................................... 11

2.6 Estrutura espacial dos genótipos............................................................... 14

2.7 Eletroforese de isoenzimas.................................................................... 15



3.1 Caracterização da área de estudo..................................................................... 17

3.2 Sistema de manejo..................................................................................... 17

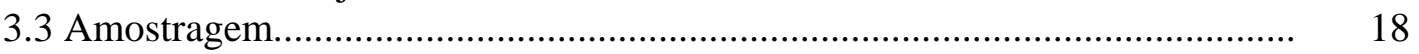

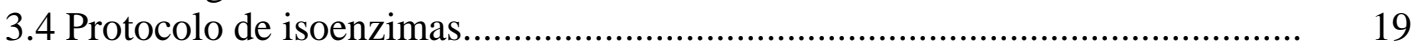

3.5 Análise Estatística..................................................................................... 21

3.5.1 Herança genética e desequilíbrio de ligação................................................. 21

3.5.2 Variabilidade genética........................................................................... 22

3.5.2.1 Freqüências alélicas.................................................................................. 22

3.5.2.2 Proporção de locos polimórficos $(\hat{P})$..................................................... 22

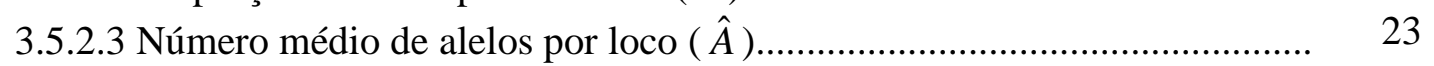

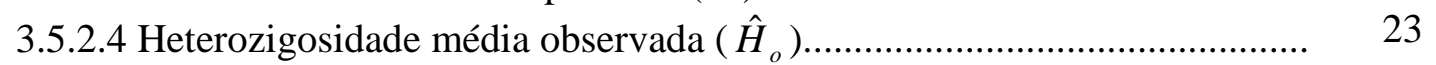

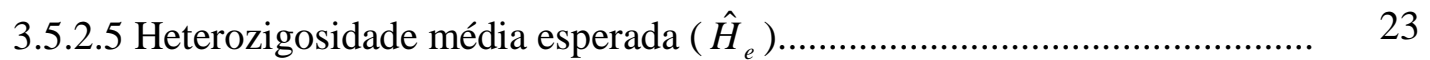

3.5.2.6 Índice de fixação de Wright $(\hat{f})$............................................................... 23

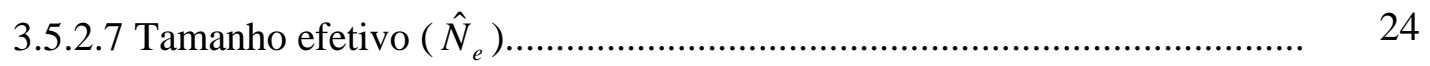

3.5.3 Sistema de reprodução............................................................................. 24

3.5.4 Estrutura espacial dos genótipos................................................................. 26

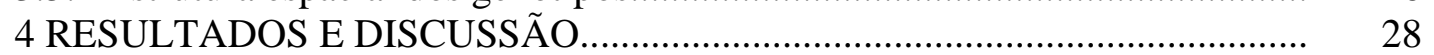

4.1 Herança genética e desequilíbrio de ligação.................................................... 28 
4.1.1 Padrões dos locos isoenzimáticos polimórficos........................................... 28

4.1.2 Segregação................................................................................................. 30

4.1.3 Desequilíbrio gamético............................................................................ 32

4.2 Variabilidade genética................................................................................. 33

4.3 Sistema de reprodução...................................................................................... 38

4.3.1 Freqüências alélicas dos óvulos e pólen...................................................... 38

4.3.2 Taxas de cruzamentos multiloco e uniloco, de cruzamento entre parentes e 38 cruzamentos correlacionados.

4.3.3 Coeficiente de coancestria e tamanho efetivo de variância........................... 41

4.4 Estrutura genética espacial.......................................................................... 45

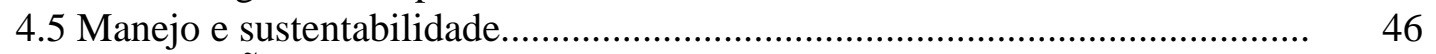

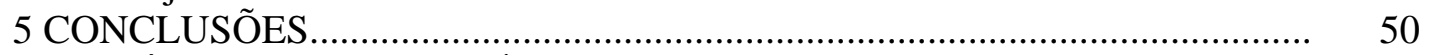

REFERÊNCIAS BIBLIOGRÁFICAS.............................................................. 


\title{
DIVERSIDADE GENÉTICA EM POPULAÇÃO NATURAL DE Eremanthus erythropappus (DC.) MACLEISH COMO BASE PARA O MANEJO FLORESTAL
}

\author{
Autor: SYBELLE BARREIRA
}

Orientador: PROF. DR. PAULO YOSHIO KAGEYAMA

\section{RESUMO}

A grande biodiversidade nas florestas tropicais, a elevada exploração de florestas e as poucas espécies estudadas do ponto de vista genético levaram a este estudo que é essencial para o manejo sustentável e a conservação genética de espécies, sendo importante no controle da redução da diversidade genética natural permitindo que as espécies se mantenham vivas e reprodutivas ao longo dos tempos. Entre as diversas espécies arbóreas brasileiras submetidas a práticas de manejo, tem-se a candeia (Eremanthus erythropappus). Os objetivos foram quantificar e comparar a variabilidade genética intrapopulacional e sistema de reprodução de candeia e antes e após o manejo, através da técnica de eletroforese de isoenzimas em uma população natural de candeia. Para as progênies as heterozigosidades observadas foram altas 0,357 e 0,423 e heterozigosidades esperadas 0,403 e 0,425. Para os adultos foram 0,299 e 0,399. A porcentagem dos locos polimórficos variou de 76 a 100\% entre progênies e adultos. O número de alelos por loco variou de 2,3 nos adultos e 
2,57 em progênies antes e após o manejo. Nas progênies não houve diferença significativa entre estes valores indicando que a população encontra-se em EHW, tal fato pode ser comprovado pelo índice de fixação significativamente igual a zero (0,112 e 0,005) antes e após manejo, respectivamente. Os resultados do sistema de reprodução foram: taxa de cruzamento alta na análise antes $(0,963)$ e pós manejo $(0,967)$ indicando que a espécie é de reprodução mista; ocorreram cruzamentos entre aparentados tanto na população antes do manejo como na pós manejo, com estimativas entre 3 e 5\%; as estimativas da correlação de autofecundação $\left(\hat{r}_{s}\right)$ foi alta nas duas populações $(0,188$ e 0,179), sendo ambas significativas, sugerindo que os indivíduos de autofecundação encontram-se aleatoriamente distribuídos nas progênies não existindo a tendência de algumas progênies apresentarem mais indivíduos de autofecundação do que outros. A correlação de paternidade foi significativamente diferente de zero $(0,414$ e 0,368), sugerindo que uma parte das progênies de cruzamentos foi gerada pelo mesmo parental materno e paterno, indicando haver a presença de cruzamentos biparentais dentro das populações. As estimativas do número médio de indivíduos polinizadores efetivos por árvore, foram baixas, em torno de 2 a 3 polinizadores por árvore. O sistema misto tem implicações na estimativa do tamanho efetivo de variância $\left(N_{e(v)}\right)$, os valores estimados para este parâmetro foram de 1,99 e 2,08 para população antes do manejo e posterior ao manejo, respectivamente. O valor estimado para o coeficiente de coancestria dentro das progênies antes do manejo $(0,229)$ e posteriores ao manejo $(0,222)$ foram superiores em 83,2\% e 77,6\% ao esperado em progênies de meios-irmãos $(0,125)$. O tamanho efetivo de endogamia foi de 178,4, 51 e 49 indivíduos em adultos, progênies antes e após o manejo, respectivamente. Os resultados indicam forte estrutura genética espacial na população, com árvores próximas até 200 m apresentando algum grau de parentesco, com 95\% de probabilidade. Estes resultados indicam que a espécie é passível de manejo e que este não afetou a diversidade nesta geração.

PALAVRAS-CHAVES: candeia, diversidade genética, manejo florestal, Eremanthus sp. 


\section{GENETIC DIVERSITY IN NATURAL POPULATION OF Eremanthus erythropappus (DC.) MacLeish AS BASIS OF FOREST MANAGEMENT}

Author: SYBELLE BARREIRA

Adviser: PROF. DR. PAULO YOSHIO KAGEYAMA

\section{SUMMARY}

The great biodiversity in the tropical forests, high level of forest exploitation and the few arboreal species which have been studied from the genetic point of view led to this study that is essential for the sustained handling and the genetic conservation of the species. They are important in controlling the natural genetic diversity reduction thus allowing the species to be alive and reproduce, in time. Among the various Brazilian arboreal species submitted to the handling practice there is the candeia (Eremanthus erythropappus). The objectives have been of quantifying and comparing the intrapopulational genetic variability and the mating system of candeia and before and after the allozyme electrophoresis technique has been applied in a natural population of candeia two different times (before and after the handling). In the progenies, the observed heterozigosity was high $(0,357$ and 0,423) and expected heterozogosity $(0,403$ and 0,425$)$. For the adults the results were $(0,299$ and 0,399$)$. The percentage of the polymorphic loci varied from $76 \%$ to $100 \%$ among progenies and adults. The number of alleles per loci varied from 2,3 in adults and 2,57 in progenies before and after the handling. In the progenies there was no significant difference 
between those values indicating that the population is in.HWE. That fact can be proven by the fixation index significantly equal to zero $(0,112$ and 0,005$)$ before and after handling, respectively. The results of the reproduction system were: the crossing rate was high in the analysis that was done before $(0,963)$ and in the one that was done after the handling $(0,967)$. The estimates of the self-fertilization correlation were high in the two populations $(0,188$ and 0,179$)$, and both were significant suggesting that the selffertilization individuals are distributed at random in the progenies and there is no tendency of some progenies to present more individuals of self fertilization than others. The paternity correlation was significantly different from zero $(0,414$ and 0,368), suggesting that a part of the progenies of crossings were bred by the same maternal and paternal begetter thus indicating that there was the presence of biparental crossings within the populations. The mixed system is involved in the average effective number variance $(\mathrm{Ne}(\mathrm{v})$, the estimated values for that parameter were of 1,99 and 2,08 for the population before the handling and after the handling, respectively. The estimated value of the coefficient of coancestry within the progenies before the handling $(0,229)$ and after the handling $(0,222)$ were superior in $83,2 \%$ and $77,6 \%$ than the expected in progenies of half-sib $(0,125)$. The effective size of inbreeding was of 178,4, 51 and 49 individuals in adults, progenies before and after the handling, respectively. The results indicate a strong spatial autocorrelation analysis in the population, with trees next to each other as far as approximately $200 \mathrm{~m}$ presenting some degree of relationship, with $95 \%$ of probability. Those results indicate that the species is unresistant to handling and that did not affect the diversity in this generation and future works must be considered to assure the sustainability of the handling that is done from the genetic point of view.

KEY WORDS: candeia, genetic diversity, forest management, Eremanthus sp. 


\section{INTRODUÇÃO}

A exploração desordenada dos ecossistemas naturais, para extração de recursos florestais ou a retirada completa de florestas para dar lugar à agricultura ou pecuária, tem gerado o desequilíbrio ambiental que culmina em grandes problemas tais como a perda de recursos hídricos e a perda de solo. Em um nível mais complexo e até hoje não levado em consideração quando se procura alcançar a sustentabilidade no manejo dos recursos naturais, esta exploração e/ou retirada completa das florestas têm levado à extinção dos recursos genéticos de diversas espécies vegetais e animais.

Devido à grande biodiversidade nas florestas tropicais e as poucas espécies pesquisadas do ponto de vista genético, estudos de como um grupo de indivíduos numa população natural se perpetua no espaço e no tempo tais como, o sistema de reprodução da espécie, quantos indivíduos são necessários para uma população manter-se viável, como é a distribuição genética espacial dos genótipos na população, como é a dinâmica da endogamia nas populações e qual é a taxa de crescimento e regeneração são essenciais para o manejo sustentado e a sua conservação genética. Estes fatores são importantes no controle da redução da diversidade genética natural e permitindo que as espécies se mantenham vivas e reprodutivas ao longo dos tempos, no ciclo evolutivo da seleção natural.

Entre as diversas espécies arbóreas brasileiras submetidas a práticas de manejo, tem-se a candeia (Eremanthus erythropappus), uma espécie arbórea comum que possui grande importância para a produção de madeira. A espécie está sendo explorada em diversas partes do Estado de Minas Gerais. Sua área de ocorrência é típica de locais montanhosos, pedregosos e solos ruins. No Estado de Minas Gerais é encontrada em Mariana, Ouro Preto, Juiz de Fora, Morro do Pilar, Carrancas, Caxambu, Aiuruoca e Baependi(Scolforo,2003). 
Manejar de forma sustentável a candeia é essencial já que, nas regiões de típica ocorrência (solos rasos e de baixa fertilidade), vem a ser uma excelente opção para agregação de renda para os agricultores que não tem, a princípio, muitas alternativas de negócio, dada à baixa potencialidade de sua região para agricultura e pecuária. Além disso, a espécie tem sido utilizada como base de sustentação de vários municípios mineiros. Pode ser entendida como geradora de emprego constante para as comunidades da região. No entanto, se por um lado à espécie é geradora de renda e emprego, por outro lado, a sua exploração é caracterizada por práticas predatórias, acarretando na diminuição da vegetação local, como a fragmentação do que resta e a provável redução na diversidade genética presente nas populações (Scolforo, 2003).

São incipientes as informações sobre os níveis de variabilidade genética da candeia e, devido à sua característica de alta densidade populacional e rápido crescimento, as seguintes hipóteses relacionadas ao manejo podem ser levantadas: $i$ ) por sua grande densidade populacional (maior que $300 \mathrm{ind}$./ha), acredita-se que os efeitos do manejo sobre a variabilidade genética sejam brandos, quando a intensidade de exploração for baixa $(<60 \%)$ e drásticos, quando intensidades de exploração aplicadas forem altas $(>60 \%)$. ii) os alelos de baixa freqüência $(<0,25)$, raros $(<0,05)$ e muito raros $(<0,01)$ são esperados. Espera-se que entre estas classes de alelos, os raros e muito raros seja perdidos por erro amostral (deriva genética), de forma que a heterozigosidade provavelmente não seja fortemente afetada pelos efeitos da exploração, na presente geração sob exploração. iii) espera-se que os maiores efeitos sejam detectados no sistema de reprodução da espécie, mais especificamente na taxa de cruzamento e na correlação de paternidade, devido ao aumento na distância espacial entre as árvores pela exploração, reduzindo, provavelmente, o tamanho da vizinhança efetivamente reprodutiva. Em termos de efeitos sobre o sistema de reprodução, espera-se um aumento na taxa de autofecundação e na correlação de paternidade, tendo como conseqüência maior endogamia por autofecundação, maior proporção de irmãos-completos, menor coeficiente de coancestria nas progênies e menor tamanho efetivo de variância e tamanho efetivo de vizinhança reprodutiva. 
O objetivo geral foi avaliar os efeitos do manejo sobre a variabilidade genética intrapopulacional, bem como no sistema de reprodução da candeia (Eremanthus erythropappus). De forma mais específica os objetivos foram:

i) quantificar e comparar a variabilidade genética intrapopulacional da candeia, antes e após o manejo sendo realizado com a espécie;

ii) estudar a distribuição espacial dos genótipos na população em questão;

iii) estudar o sistema de reprodução da espécie após o manejo através de marcadores genéticos bioquímicos;

iv) propor indicativos de sustentabilidade do manejo sob o ponto de vista genético e ecológico. 


\section{REVISÃO DE LITERATURA}

\subsection{Caracterização da espécie}

A candeia (Eremanthus erythropappus) é uma espécie arbórea de grande importância e que está sendo centro de atenção em diversas partes do Estado de Minas Gerais. Pertencente ao grupo ecológico das pioneiras, (Carvalho, 1994) e mais especificamente uma pioneira antrópica, espécie capaz de ocupar locais antropizados. Seu crescimento é rápido em campos abertos, formando povoamentos mais ou menos puros. Macleish (1987) cita que a candeia atinge até $10 \mathrm{~m}$ de altura mas, segundo Cândido (1991), em plantios uniformes podem atingir alturas um pouco maiores do que $12 \mathrm{~m}$. A casca é grossa e cheia de fendas no fuste. As folhas têm uma característica marcante que é a dupla coloração, na parte superior são verdes e glabras e na parte inferior possuem um tom branco, tomentoso e são aveludadas (Corrêa, 1931).

Quanto à reprodução as flores da candeia se apresentam em inflorescências de cor púrpura nas extremidades dos ramos (Araújo, 1944). O fruto é do tipo aquênio, com superfície cilíndrica, de cor pardo-escura, com aproximadamente $2 \mathrm{~mm}$ de comprimento. Cada fruto contém apenas uma semente. A percentagem de germinação na ausência de luz é de 6\% e na ausência de luz 0\% (Chaves e Ramalho, 1996).

O mecanismo de dispersão que contribui com a regeneração natural da candeia é a anemocoria (CETEC, 1994). O estágio sucessional da floresta, o solo e a posição geográfica das áreas também interferem no recrutamento das plântulas de candeia.

O sombreamento é um dos fatores que afeta a regeneração por semente. Pedralli, Teixeira e Nunes (1996), estudando a sinecologia da candeia na Estação Ecológica do Tripuí, em Ouro Preto, MG, compararam o recrutamento de indivíduos de candeia em banco de sementes simulando duas condições de campo: uma a plena luz, regando duas 
vezes por dia, e a outra na sombra, regando uma vez. Os resultados confirmaram que o fracasso da germinação de quase todas as sementes está diretamente ligado ao fator luz, sendo que o número total de plântulas de candeiais recrutadas foi de 121 na luz e de 16 nas condições de sombreamento.

Conforme MacLeish (1987), a candeia atinge até 10m de altura. Já Teixeira et al. (1996) citam que a candeia é uma árvore pequena de até $6 \mathrm{~m}$ de altura e $50 \mathrm{~cm}$ de diâmetro. Estudos do CETEC (1994), na estação Ecológica do Tripuí, identificaram indivíduos de candeia de até $77 \mathrm{~cm}$ de CAP e $14 \mathrm{~m}$ de altura.

Na estação Ecológica de Tripuí, Pedralli (1997), analisou a estrutura comunitária dos candeiais utilizando as distribuições de diâmetro e altura e o crescimento da espécie. Por meio da análise comparativa dos diâmetros, verificaram que 32,15\% das árvores amostradas apresentavam diâmetro entre 10,1 e $20 \mathrm{~cm}$ e que mais de $68 \%$ delas possuíam diâmetros que variavam entre 5 e $30 \mathrm{~cm}$. Para a altura, observou-se que no estrato compreendido entre 4,1 e 10m encontravam-se $81,27 \%$ das árvores, sendo predominante o estrato de 6,1 a $8 \mathrm{~m}$, com $39 \%$ dos indivíduos. Os maiores exemplares da área atingiram $12 \mathrm{~m}$ de altura.

A sua área de abrangência é predominante em locais montanhosos, pedregosos com solo ruim, os quais não são empecilhos para o seu desenvolvimento. É muito comum encontrar grandes candeiais em locais em que seria difícil o desenvolvimento de outra espécie arbórea ou de uma cultura agrícola.

Carvalho (1994) cita que a candeia ocorre na América do Sul, sendo encontrada no nordeste da Argentina, norte e leste do Paraguai e no Brasil. Pedralli, Teixeira e Nunes (1996) indicam que se pode encontrar a candeia no Brasil, nos estados de Minas Gerais, Bahia, Espírito Santo e Rio de Janeiro. Carvalho (1994) cita outros estados nos quais também a candeia vegeta, como Goiás, Paraná, Rio Grande do Sul, Santa Catarina, São Paulo, e também o Distrito federal. No estado de Minas Gerais é encontrada em Mariana, Ouro Preto, Juiz de Fora, Morro do Pilar, Carrancas, Caxambu, Baependi e Aiuruoca. 
A candeia é utilizada em diversos usos: construção naval, construção de canoas, lenha, postes e muito utilizada como moirão para cercas. Atualmente, um dos principais usos desta espécie é para a extração de óleo, o qual tem alto valor de mercado.

A madeira da candeia é dura, resistente e apresenta odor de ácidos valerianos e um óleo essencial cujo princípio ativo é o $\alpha$-bisabolol, que exibe propriedades antinflamatórias, antibacterianas, antimicóticas, dermatológicas e espasmódicas (Teixeira et al., 1996), sendo o quilo do óleo bruto e do óleo refinado comercializados a US\$ 18,00 e US\$ 60,00, respectivamente. O preço do metro estéreo de madeira para extração do óleo fica entre $\mathrm{R} \$ 60,00$ e R \$ 80,00. A madeira da candeia é empregada em diversos usos: construção naval, construção de canoas, lenha, postes e muito utilizada como moirão para cercas, cuja dúzia atualmente é paga a $R \$ 35,00(2,2 \mathrm{~m}$ de comprimento e, em média, $10 \mathrm{~cm}$ de diâmetro).

\subsection{Biodiversidade e Manejo}

A conservação da biodiversidade da floresta tropical se torna muito importante, quando se busca compreendê-la pelo conhecimento das interações biológicas, caracterizando a reprodução, a sucessão ecológica e a estrutura das populações (ecologia e genética), além de fornecer parâmetros confiáveis na busca da conservação, do manejo e da restauração das espécies. O Brasil é um país com elevada biodiversidade e possui áreas denominadas de"Hotspot”, que apresentam elevada diversidade e elevada pressão antrópica, indicando necessidades prioritárias de conservação (Kageyama, 2001). Segundo Myers (1988), o Brasil possui dois "hotspots", sendo constituído pela Floresta Atlântica e pela Floresta Amazônica.

Para Kricher (1990), o número de espécies animais e microorganismos na floresta tropical é 100 vezes superiores ao de espécies vegetais, verificando-se que ocorreu uma coevolução na diversidade, correspondendo as espécies de planta um número muito superior ao número de animais, sugerindo que os compostos secundários químicos dos vegetais foram utilizados para sua defesa contra os inimigos naturais. Esse fato contribui para o desenvolvimento da biotecnologia, na qual o uso racional desses recursos naturais pela industria farmacêutica e química contribui para sua valorização 
(Kageyama, 2001).

Parâmetros genéticos e ecológicos são importantes para o manejo sustentável das florestas tropicais, na qual a possibilidade de retomada de crescimento (regeneração, recrutamento) de uma população deverá ser conhecida, a fim de proporcionar novos ciclos de exploração, na busca de manter a integridade das populações, verificando-se que algumas espécies apresentam características que as caracterizam como comuns, e outros como raras. Questões referentes à raridade, dimensão da árvore e o material que será explorado deverão ser conhecidas para que o manejo dos recursos da floresta seja sustentável, além da necessidade de abranger critérios econômicos e sociais (Kageyama, 2000). Além disso, o conhecimento da taxa de crescimento é fundamental para o efetivo manejo sustentado.

\subsection{Diversidade genética em espécies arbóreas}

Segundo Hamrick (1983) e Loveless \& Hamrick (1987), o estudo da diversidade genética em populações naturais compreende a descrição dos níveis de variação genética mantida dentro das populações, bem como a forma em que a variação genética é dividida entre as populações. A diversidade genética e a estrutura genética de populações podem ser caracterizadas usando-se caracteres quantitativos, avaliados em testes de procedências e progênies, e com base em dados de marcadores genéticos. A técnica de eletroforese de isoenzimas apresenta algumas vantagens sobre os métodos clássicos de genética quantitativos nessas análises, como: a herança genética das características detectadas poder ser facilmente demonstrada; a maioria dos locos são codominantes e as freqüências gênicas podem ser calculadas diretamente sem a necessidade de cruzamentos genéticos; além disto, as estimativas da variabilidade genética podem ser comparadas diretamente entre populações e um conjunto de locos pode ser acessado usando-se pequena quantidade de material (Hamrick et al., 1979; Hamrick, 1989).

A diversidade genética intrapopulacional pode ser caracterizada pelos índices porcentagem de locos polimórficos $(\hat{P})$, número médio de alelos por loco $(\hat{A})$, 
heterozigosidade esperada em equilíbrio de Hardy-Weinberg $\left(\hat{H}_{e}\right)$, heterozigosidade observada $\left(\hat{H}_{o}\right)$ e índice de fixação $(\hat{f})$ (Berg \& Hamrick, 1997). Hamrick \& Godt (1990) reportam heterozigosidade media esperada de 0,123 para espécies com dispersão anemocórica e de 0,124 para espécies polinizadas por animais. Loveless \& Hamrick (1984) comentam que as espécies tipicamente alógamas apresentam alta variação genética dentro e pequena entre populações, sendo que a divergência entre é tanto menor quanto maior for o fluxo gênico.

Verifica-se que em populações de baixa densidade de indivíduos a ocorrência de fenômenos genéticos como a deriva genética, que provoca perda da variação genética rapidamente em pequenas populações e a endogamia (auto-fecundações e cruzamento entre indivíduos aparentados) ocasionam a perda da heterozigosidade. Portanto, para a efetiva conservação genética ou exploração de uma espécie deve-se conhecer a forma em que a variação genética ocorre entre e dentro das populações, bem com o entendimento dessa variação no tempo e no espaço. Estudos da estrutura intrapopulacional de espécies arbóreas têm demonstrado que a distribuição de alelos e genótipos não é aleatória dentro das populações (Coles \& Fowler, 1976; Loveless \& Hamrick, 1984; Chung \& Epperson, 2000). Tal estrutura pode ser determinada pela dispersão de pólen e sementes, habitat de distribuição e seleção microambiental (Hamrick, 1983).

A relação temporal e espacial entre indivíduos próximos aumenta a probabilidade de intercruzamento e se os mecanismos de dispersão de pólen e sementes forem restritos a uma pequena vizinhança, aumentam as chances destes indivíduos serem aparentados (Coles \& Fowler, 1976). O cruzamento entre parentes gera endogamia, apesar de ser uma forma menos drástica do que a autofecundação efetiva, porém é a única forma de ocorrência de endogamia em espécies que apresentam sexos separados (Allard, 1971).

Muito da endogamia observada dentro de populações naturais de espécies florestais é determinado pela distância e taxa com que os genes migram dentro e entre populações (Coles \& Fowler, 1976). A outra parte, é determinada por seu sistema de reprodução, mais especificamente pela taxa de autofecundação. Se o movimento de 
genes é extenso, resultando em fluxo gênico a longa distância, é esperada baixa endogamia dentro das populações e baixa divergência genética entre populações. Se, contudo, o fluxo de genes efetivo é limitado e a troca gênica entre árvores vizinhas é comum, pode ocorrer uma alta proporção de endogamia dentro das populações e alta divergência entre populações (Coles \& Fowler, 1976). Entretanto, caso o movimento de genes via pólen seja longo e via sementes seja restrito, é esperada baixa endogamia dentro das populações, moderados níveis de divergência genética entre populações, mas alto parentesco dentro das populações (população estruturada em famílias).

Espécies arbóreas geralmente possuem um grau relativamente alto de variações genéticas, isso quando comparadas com outras plantas e espécies animais (Mitton, 1983; Ledig, 1986). Este grau alto de variação ao nível molecular de variantes de isoenzimas freqüentemente é assumido como um reflexo de recentes eventos históricos e do sistema de reprodução, mais do que o resultado de adaptações ambientais que coletivamente definem a estrutura genética de uma população (Ledig, 1986). Após um evento natural ou de um manejo da floresta, poderá ocorrer um efeito denominado de estrutura de famílias, ou seja, um fenômeno que está associado à forma em que os genes estão distribuídos no espaço, formando sub-populações ou demes homogêneas, aumentando as chances de ocorrer cruzamentos entre aparentados, levando à fixação de alelos raros, deriva genética e à indução de endogamia, promovendo um aumento da divergência genética entre populações (Young et al., 1996).

A diferenciação entre as populações é aumentada pela seleção e deriva genética, sendo que espécies com elevado movimento de pólen e sementes, em geral, possui menor diferenciação do que espécies com fluxo gênico restrito (Hamrick, 1989). Kageyama \& Lepsch-Cunha (2001) discutem que o fluxo gênico via pólen e sementes têm demonstrado estar associados à estrutura genética das populações de espécies arbóreas tropicais, na qual à distância do vôo dos polinizadores e dispersores pode predizer a variação genética dessas espécies.

Hamrick (1983) discute que o padrão genético da floresta tropical é afetado por processos como a dispersão de pólen e sementes, estágios sucessionais e o sistema reprodutivo, que devem ser analisados, e que influencia a distribuição espacial da 
variabilidade genética entre e dentro das populações das árvores em uma floresta contínua. Ressalta também que plantas em estágios iniciais de sucessão possuem maior distância genética entre populações e com fluxo gênico mais restrito, o contrário das espécies de final de sucessão. Moraes (1993) encontrou esse padrão para a aroeira (Myracroduon urundeuva), a qual é considerada rara e apresenta pequena variabilidade genética entre as populações.

\subsection{Sistema de reprodução de espécies arbóreas tropicais}

O estudo do sistema de reprodução permite estimar a taxa de cruzamento entre indivíduos, determinando o modo de transmissão de genes de uma geração à próxima (Brown,1990). Relevância é dada ao pioneiro trabalho realizado por Bawa (1974) que, estudando o sistema de reprodução em espécies arbóreas tropicais da Costa Rica, através de polinização controlada e observações da biologia floral, verificou apresentarem, em um total de 130 espécies estudadas, 14\% espécies autocompatíveis, 54\% autoincompatíveis, $68 \%$ hermafroditas, $22 \%$ dióicas e 10\% monóicas. Marcadores isoenzimáticos ou moleculares vêm sendo utilizado com grande eficiência nos estudos de sistemas de determinação de reprodução em espécies arbóreas tropicais, as quais têm demonstrado ser na grande maioria alógamas, ou de sistema misto com predomínio de alogamia (O'Malley \& Bawa 1987, Murawski et al. 1990, Murawski 1995).

Diferente das espécies predominantemente de autofecundação, onde a maior parte de sua variabilidade genética está distribuída entre populações, espécies de cruzamento mantêm a maior parte da variabilidade dentro e menor entre populações, (Hamrick 1983, Hamrick \& Godt, 1989). Deve-se prever maior heterozigosidade dentro e reduzidos níveis de divergência genética entre populações, devido ao intenso fluxo de pólen entre populações e grandes tamanhos efetivos e de vizinhança com reduzida subdivisão dentro de populações (Sebbenn et al 2001). O sistema misto de reprodução prediz variabilidade genética intermediária entre espécies de autofecundação e alógamas, sendo o potencial de diferenciação entre populações variável em função do balanço dessas duas formas de reprodução (Loveless \& Hamrick, 1984). 
Dois modelos têm sido utilizados para caracterização dos sistemas de cruzamento, o modelo de cruzamento aleatório e o modelo misto de reprodução, sendo o segundo o modelo mais difundido para avaliação do sistema de reprodução em plantas a partir de dados de marcadores genéticos (Clegg, 1980). As pressuposições básicas para a aplicação do modelo misto são: (a) que os genótipos foram gerados por cruzamento aleatórios ou autofecundação; (b) que as freqüências alélicas do pólen são homogêneas para todos os cruzamentos com genótipos maternos; (c) que a taxa de cruzamento é independente do genótipo materno; e (d) que não existe seleção atuando nos marcadores entre o período de cruzamentos e avaliação genética das progênies. (Ritland \& Jain, 1981; Ritland, 1990).

O sistema de reprodução, juntamente com os mecanismos de dispersão de pólen e sementes, tem papel fundamental na determinação da estrutura genética espacial e temporal das populações (Hamrick, 1983; Hamrick \& Lovelless, 1986). Portanto, o conhecimento da forma de reprodução de uma espécie é de fundamental importância em programas de melhoramento e conservação genética, pois permite delinear estratégias que otimizem a amostragem da variabilidade genética e a adoção de modelos genéticosestatísticos adequados para a estimativa de parâmetros genéticos (Souza, 2003). Da mesma forma é também importante determinar estratégias de manejo de populações em áreas naturais, de modo que sejam mantidos os mecanismos de manutenção da diversidade genética das espécies.

\subsection{Manejo na diversidade genética de espécies arbóreas}

Humanos têm convertido florestas para usos na agricultura e em áreas urbanas, explorando espécies, fragmentando as terras selvagens, mudado a estrutura demográfica das florestas, alterando o habitat, degradando o ambiente e poluindo a atmosfera e o solo, assim como introduzindo pestes exóticas e favorecendo espécies domesticadas. Nenhuma dessas atividades é nova, sendo que, com exceção da poluição atmosférica, elas datam da pré-história. Todas têm impactado a diversidade genética (exemplo, diversidade de espécies e diversidade genética dentro de espécies) pelas suas influências sobre os processos evolutivos de extinção, seleção, deriva, fluxo gênico e mutação, 
algumas vezes aumentando a diversidade como em alguns casos de domesticação, mas outras vezes reduzindo a diversidade genética. Mesmo na ausência de mudanças na diversidade genética, o sistema de reprodução tem sido alterado, mudando a estrutura genética das populações (Ledig, 1992).

A diversidade genética promove a matéria prima para a adaptação, a evolução e a sobrevivência das espécies e indivíduos, especialmente sobre mudanças ambientais e condições de doenças. A variabilidade genética é também a base para o melhoramento genético. Como as espécies arbóreas são normalmente espécies chaves dos ecossistemas florestais, devido à sua vida longa, sua diversidade genética tem um significado especial. Redução na diversidade genética pode predispor as espécies a doenças, reduzir a produtividade e limitar o melhoramento genético. Assim, a diversidade genética pode ser vista como fundamental para a sustentabilidade e estabilidade do ecossistema.

O manejo florestal sustentado e a exploração ordenada das florestas naturais e plantadas visam a produção contínua de madeira, resina, gomas, etc. Para atingir este objetivo os programas de manejo devem ser delineados com base em medidas de incremento médio anual (IMA), incremento corrente anual (ICA), obtidos em inventários contínuos em amostras dos diversos tipos de sítios (solo) em que o plano de manejo é desenvolvido. Contudo, o manejo de populações naturais também deve considerar a constituição genotípica dos indivíduos das espécies alvo da exploração, a qual é a responsável por parte das diferenças de produtividade, adaptação e reprodução entre indivíduos de uma espécie. No entanto, apesar da grande importância destes fatores genéticos para a exploração sustentada de uma espécie, os planos de manejo em florestas tropicais naturais não tem incorporado estes fatores (Sebbenn et al., 2000). Há uma falta de preocupação em desenvolver um modelo que incorpore o componente genético; isto seria primordial para a real efetivação da sustentabilidade.

O manejo de espécies arbóreas tropicais para a produção sustentável depende do entendimento dos efeitos das práticas de exploração sobre a reprodução contínua das árvores e a manutenção da diversidade genética. $\mathrm{O}$ manejo seletivo envolve a extração de uma proporção de árvores de tamanho reprodutivo (Murawski et al, 1994). Essa 
prática necessariamente reduz a densidade populacional local de florescimento que, em termos, pode reduzir a densidade de polinizadores (Bawa, 1991; Murawski, 1995).

Muraswki et al. (1994), estudando os efeitos do manejo sobre o sistema de reprodução de uma espécie arbórea tropical de dossel endêmica da Sri Lanka, compararam uma população manejada com uma não manejada. Detectaram maior taxa de autofecundação na população manejada $(0,290)$ em comparação à não manejada $(0,130)$. Sebbenn et al. (2001) comparando o sistema de reprodução de uma população manejada e uma não manejada (natural) de Tabebuia cassinoides, constataram maior taxa de autofecundação $(0,217)$ na população manejada relativamente a natural $(0,105)$. Efeitos ainda mais drásticos foram detectados por Obayashi et al. (2002), comparando o sistema de reprodução de uma população natural e uma manejada de Shorea curtisi; a taxa de autofecundação foi de 0,478 na população manejada e de 0,037 na população não manejada.

A causa das maiores taxas de autofecundações em populações manejadas pode estar associada ao fato de que o manejo reduz a densidade de árvores reprodutivamente maduras em áreas manejadas, podendo afetar o comportamento dos polinizadores de tal forma, que seu movimento tende a ocorrer predominantemente dentro da copa das árvores. Outro aspecto importante foi detectado por Sebbenn et al. (2001), que observaram haver uma correlação de paternidade ou a proporção de progênies de cruzamentos gerando irmãos-completos sendo de $54,7 \%$ na população não manejada e de $29,5 \%$ na manejada. Isso indica que a parte da reprodução que ocorreu por cruzamento na população manejada foi mais aleatória comparativamente à população não manejada. Isto pode ter sua causa atribuída ao mesmo fator que favoreceu a maior taxa de auto-fecundação, ou seja, a redução na densidade populacional poderia ter favorecido a visita de vários polinizadores às copas das árvores devido a escassez de flores. Outro aspecto ainda observado por Sebbenn et al. (2001) foi que a taxa de cruzamento endogâmicos foi menor na população manejada $(0,092)$ em relação à não manejada $(0,175)$.

Os autores atribuíram isto ao fato de que o manejo elimina parte da população, de forma que se esta apresentar estrutura genética espacial, muito do parentesco 
intrapopulacional será removido, reduzindo a probabilidade de ocorrerem cruzamento entre indivíduos parentes e gerar endogamia biparental. Por outro lado, os resultados de Murawski et al. (1994) observaram maior taxa de cruzamento entre indivíduos parentes em uma população manejada $(0,062)$, em comparação a uma natural $(0,017)$ de Shorea curtisi, atribuindo o fato à possibilidade de que em populações manejadas indivíduos próximos possam ser menos parentes entre si do que populações não manejadas.

\subsection{Estrutura espacial dos genótipos}

Gandara (1996) destaca a importância do conhecimento da estrutura genética espacial para o estabelecimento de estratégias de amostragem de populações naturais, tanto para a conservação genética quanto para fins de melhoramento, possibilitando a formação de amostras significativas. Cita também a importância deste conhecimento para minimizar o impacto de práticas de manejo na sustentabilidade dos recursos genéticos.

Estudos na estrutura intrapopulacional de espécies arbóreas têm demonstrado que a distribuição de alelos e genótipos não é aleatória dentro das populações. Tal estrutura pode ser determinada pela dispersão de pólen e sementes, habitat de distribuição e seleção micro ambiental (Hamrick, 1983). Isto porque a freqüência alélica na próxima geração, será influenciada pelo número de indivíduos que efetivamente trocarão alelos.

Especialmente em pequenas populações a taxa de homozigotos tenderá a crescer com a autofecundação, com os cruzamentos de indivíduos aparentados assim como entre indivíduos similares que ficaram próximos em decorrência de dispersão de pólen e sementes à curta distância. Estes cruzamentos, segundo Wright (1978), proporcionam a formação de demes panmíticas o que reduz a proporção de heterozigotos na população, a qual pode ser quantificada pelo índice de fixação, a partir do teorema de HardyWeinberg.

Futuyma (1992) comenta que, como em uma população existem limitações físicas que não permitem o cruzamento de todos com todos, ou seja, aleatória, deverá haver maior probabilidade de cruzamentos entre indivíduos próximos, levando a redução dos heterozigotos e formação dos grupos, estruturando a população. Estes cruzamentos 
preferenciais conduzirão à fixação de certos alelos; assim, por deriva genética ou endogamia, haverá formação de diferentes grupos, formando-se sub-populações (Alves, 2002).

\subsection{Eletroforese de isoenzimas}

Uma ferramenta que tem sido usada com grande eficiência para a análise do sistema de reprodução e da estrutura genética de populações de espécies de plantas é a técnica de eletroforese de isoenzimas, tendo sido empregada na grande maioria dos estudos populacionais com plantas. A eletroforese de isoenzimas consiste na migração de enzimas em um gel submetido à influência de um campo elétrico, na qual o produto enzimático resultante da ação de diferentes alelos é denominado de isoenzimas (Gandara, 1996). Para tal, emprega-se extratos protéicos obtidos por maceração do tecido vegetal em soluções extratoras apropriadas. Em seguida, os géis serão fatiados e revelados, visando a presença de proteínas totais ou enzimas específicas. Para isto, os géis são incubados em soluções específicas, contendo os componentes (substrato, coenzimas, solução-tampão e sais) necessários para a revelação das bandas de atividade enzimática visualizadas no gel, denominadas isoenzimas, sendo o conjunto de bandas reveladas nos géis denominadas de zimograma. A variação na intensidade de bandas é função da atividade enzimática, da estrutura quaternária da enzima, do número de loco e número de alelo no loco que contribuem para a síntese da enzima (Alfenas et al., 1991). A taxa de migração é determinada pelo tamanho, forma e carga da proteína. As isoenzimas são controladas geneticamente por um ou vários genes, situados num mesmo loco ou em diferentes locos (Alfenas, 1998).

Os marcadores genéticos apresentam diversas aplicações na conservação genética dos recursos florestais, por meio da mensuração da diversidade genética, estimativas das taxas de fluxo gênico ou migração, caracterização do sistema de reprodução, análise de paternidade, avaliação da eficiência do pomar de sementes, estudos filogenéticos e taxonômicos, podendo ser mensuradas diferenças genéticas em populações naturais e manejadas (Glaubitz \& Moran, 2000). Outra vantagem da eletroforese de isoenzimas seria: permitir a caracterização da estrutura genética das 
populações, em curto espaço de tempo, não exigir área experimental, limite no número de populações a serem estudadas e os custos equivalerem aos métodos clássicos de experimentação de campo, além de as enzimas serem a expressão direta dos genes, o que aumenta a precisão das estimativas dos parâmetros genéticos (Stebbins, 1989).

Diversas foram as espécies arbóreas tropicais cuja diversidade e sistema reprodutivo foram estudados a partir de marcadores tais como, Aspidosperma polyneuron (Maltez, 1997), Calophyllum brasiliense (Kawaguici, 1999), Chorisia speciosa (Souza, 1997), Couratari multiflora (Lepsch Cunha, 1996), Cedrela fissilis (Gandara, 1996), Euterpe edulis (Reis, 1996), Hymenaea Courbaril (Santos, 2002), Eschweilera ovata (Gusson, 2003), Tabebuia cassinoides (Cavallari Neto, 2004), Trema micrantha (Ribas 2003), Cecropia pachystachya (Ribas, 2003), Esenbeckia leiocarpa (Seoane et al., 2001). 


\section{MATERIAIS E MÉTODOS}

\subsection{Caracterização da área de estudo}

A área de estudo localiza-se na Fazenda Bela Vista, no município de Baependi, estado de Minas Gerais, nas coordenadas de $21^{0} 58^{\prime} 23^{\prime \prime}$ de latitude sul e $44^{0} 44^{\prime} 35^{\prime \prime}$ de longitude oeste. A altitude varia de 1.350 a $1.700 \mathrm{~m}$. O clima, na classificação de Köppen, é mesotérmico úmido do tipo $\mathrm{Cwb}$, tropical de altitude, com verões suaves. A temperatura do mês mais quente é inferior a $22^{\circ} \mathrm{C}$, a temperatura média anual varia entre $18^{0}$ e $19^{0} \mathrm{C}$. e a média anual de precipitação pluviométrica é da ordem de $1.400 \mathrm{~mm}$. Os meses mais chuvosos correspondem a dezembro, janeiro e fevereiro, e as menores precipitações ocorrem em junho, julho e agosto. Na região predomina o solo Latossolo Vermelho-Amarelo.

A vegetação característica é do tipo Campo cerrado, Mata de Galeria e Floresta Semi-Decídua Montana.

\subsection{Sistema de manejo}

O sistema de manejo utilizado para a candeia é o de corte seletivo, para o qual as seguintes informações foram utilizadas: inventário florestal, análise da estrutura da vegetação, ritmo de crescimento em diâmetro das árvores, critério de floresta balanceada (Scolforo 2003).

O método silvicultural que mais se aproxima ao manejo desejável para esta espécie é o que se baseia no Método de transformação por via da Sucessão dirigida já que é uma espécie pioneira e cujo aproveitamento para fins comerciais deve ser restrito a áreas homogêneas com a espécie ou nas bordas das matas. O sistema avaliado por este estudo foi o de porta sementes com regeneração natural. O sucesso deste sistema depende de 
uma regeneração natural intensa o que deve ser garantido pela dispersão de sementes a partir de árvores porta sementes.

A intensidade de exploração foi alta (300 ind/ha) com a manutenção na área de matrizes (porta-sementes) a fim de garantir a regeneração natural.

\subsection{Amostragem}

Uma área de aproximadamente 20 ha foi selecionada para o estudo, considerada como uma população de candeia. A amostragem foi executada em dois momentos (pré e pós manejo) nesta mesma área. Num primeiro momento foram coletadas amostras foliares de 213 indivíduos considerados adultos (indivíduos que apresentarem DAP $\geq$ $5 \mathrm{~cm})$, distribuídos nos 20 ha, antes do manejo ser executado.

Para a caracterização dos sistema de reprodução, coletou-se sementes de 30 matrizes adultas distribuídas nos 20 ha, antes do manejo ser executado e de 30 matrizes adultas onde o manejo foi executado.

As sementes foram colocadas para germinar em tubetes (caixa com 96 células) separadas por matriz e em casa de vegetação com sistema de irrigação. A germinação ocorreu aos 8 dias aproximadamente. Aos 15 dias após a germinação as plântulas já puderam ser analisadas. De cada matriz foram genotipadas 15 plântulas, totalizando 900 plântulas analisadas (30 matrizes x 15 progênies x 2 coletas)

De acordo com Sebbenn et al (2001), o tamanho amostral para a estimativa de freqüências alélicas e índices de diversidade genética de uma população está entre 60 a 100 indivíduos. Já para uma população estruturada em progênies, quando a espécie for alógama ou reprodução mista, deve ser feita a amostragem de 30 progênies com pelo menos 10 plantas por progênie.

Todos os indivíduos que tiveram material coletado (tecidos foliares ou sementes) foram georeferenciados, com o auxílio de um aparelho de GPS, para fins de análise de estrutura espacial. 


\subsection{Protocolo de isoenzimas}

O protocolo para os sistemas enzimáticos de candeia foi baseado em Alfenas et al. (1991), com adaptações para a referida espécie.

Para a análise de eletroforese de isoenzimas foram utilizadas amostras foliares dos indivíduos adultos. As amostras foram transportadas para Laboratório de Genética e Reprodução de Espécies Arbóreas (LARGEA) - no Departamento de Ciências Florestais ESALQ/USP em caixas de isopor com gelo, procedimento utilizado para evitar modificações bioquímicas (degradação das enzimas). Foram testados sistemas de tampão de extração e cuba/gel em vários sistemas enzimáticos.

As amostras puderam ficar armazenadas por no máximo três dias e após este período começavam a oxidar. Foi realizada uma extração teste com dois tampões (Alfenas, 1991 e Soltis, 1989). Após a eletroforese constatou-se que o tampão Alfenas (1991) apresentava melhor padrão de revelação, sendo, portanto, adotado como o tampão a ser utilizado em todas as extrações. A composição da solução pode ser observada na Tabela 1.

Após a escolha do tampão de extração, as demais amostras foram extraídas embebidas em wicks (papel whatman n.3), colocados em micro tubos e armazenados em freezer $\left(-80^{\circ} \mathrm{C}\right)$.

Tabela1. Composição da solução utilizada na extração de enzimas de Eremanthus erythropappus, conforme Alfenas (1991)

\begin{tabular}{lc}
\hline \multicolumn{1}{c}{ Reagente } & Quantidade \\
\hline Fosfato de sódio dibásico & $0,6 \mathrm{~g}$ \\
Sacarose & $7 \mathrm{~g}$ \\
Polivinil pirolidona PVP-40 & $2,56 \mathrm{~g}$ \\
L-ácido ascórbico & $100 \mathrm{mg}$ \\
Dietilditiocarbamato DIECA & $100 \mathrm{mg}$ \\
Bissulfito de sódio & $50 \mathrm{mg}$ \\
Borato de sódio & $50 \mathrm{mg}$ \\
Polietilenoglicol -6000 & $1 \mathrm{~g}$ \\
Mercaptoetanol & $1-2 \mathrm{ml}$ \\
Água destilada (q.s.p.) & $100 \mathrm{ml}$ \\
\hline
\end{tabular}


Foram testados 27 sistemas de coloração descritos na Tabela 2 para quatro sistemas de tampão gel/ eletrodo (Citrato Morfolina (CM, Histidina (25), Lítio/Borato (19) e Tris Citrato (TC)) em gel horizontal de amido de milho (penetrose) e amido de batata a $13 \%$ de amido. Em cada gel foram colocadas 20 amostras e 3 wicks com azul de bromofenol para marcar distância de migração.

Tabela 2. Enzimas testadas e seus respectivos códigos, para determinação do protocolo para Eremanthus erythropappus, Alfenas (1991)

\begin{tabular}{ll}
\hline \multicolumn{1}{c}{ Enzima } & \multicolumn{1}{c}{ Código } \\
\hline Esterase & $\alpha$ EST - EC. 3.1.1.1 \\
Malato Desidrogenase & MDH - EC 1.1.1.37 \\
$\beta$ - Glucosidade & $\beta$ - GLU - EC 3.2.1.21 \\
Fumarase & FUM - EC 4.2.1.2 \\
Galactose desidrogenase & GLDH - EC 1.1.1.48 \\
6-fosfogluconato desidrogenase & 6PGDH - EC 1.1.1.44 \\
Leucina aminopeptidase & LAP - EC 3.4.11.1 \\
Menadinona redutase & MR - EC 1.6.99.3 \\
Fosfatase ácida & ACP - EC 3.1.3.2 \\
Glutamato desidrogenase & GDH - EC 1.4.1.3 \\
Isocitrato desidrogenase & IDH - EC 1.1.1.42 \\
Fosfoglucose isomerase & PGI - EC 5.3.1.9 \\
Lactato desidrogenase & LDH - EC 1.1.1.27 \\
Glucose-6-fosfato desidrogenase & G6PDH - EC 1.1.1.44 \\
Álcool desidrogenase & ADH - EC 1.1.1.1 \\
Nicotinamida adenina dinucleotídeo desidrogenase & NADHDH - EC 1.6.99.3 \\
Glutamato-oxaloacetato transamitase & GOT - EC 2.6.1.1 \\
Diaforase & DIA - EC 1.6.4.3 \\
Peroxidase & PO - EC 1.11.1.7 \\
Fosfoglucomutase & PGM - EC 2.7.5.1 \\
Xiquimato desidrogenase & SKDH - EC 1.1.1.25 \\
Sorbitol desidrogenase & SDH - EC 1.1.1.14 \\
Fosfatase alcalina & ALP - EC 3.3.3.1 \\
Superóxido dismutase & SOD - EC 1.15.1.1 \\
Glicerato 2 desidrogenase & G2DH-EC 1.1.1.29 \\
Manitol desidrogenase & MADH- EC 1.1.1.67 \\
Peroxidase método II & POII- EC 1.11.1.7 \\
\hline
\end{tabular}


Dos tampões gel/eletrodo testados o Citrato Morfolina $\mathrm{pH} 7,1 / 6,1$ foi o que apresentou melhor resolução das bandas para 13 sistemas enzimáticos quando o material utilizado foi obtido dos indivíduos adultos, ( $\alpha$-EST, ACP, PGI, 6PGDH, PGM, SKDH, G6PDH, LAP, DIA, GOT, NADHDH, MR, MDH) pois apresentaram ótima atividade e resolução das bandas passíveis de interpretação. Também para o material obtido das progênies o tampão gel/eletrodo Citrato Morfolina $\mathrm{pH}$ 7,1/6,1 foi o que apresentou melhor resolução das bandas. No entanto, os sistemas não se mantiveram e sete deles tiveram ótima atividade e resolução das bandas para interpretação ( $\alpha$-EST, ACP, PGI, 6PGDH, PGM, G6PDH, DIA).

\subsection{Análise Estatística}

\subsubsection{Herança genética e desequilíbrio de ligação}

Não foram realizados cruzamentos controlados para o estudo da herança isoenzimática em E. erythropappus. Assim, adotou-se o método descrito por Gillet \& Hattemer (1989), que compara o genótipo de árvore materna com a segregação de suas progênies de polinização aberta. As seguintes condições devem ser satisfeitas: a) toda progênie de uma árvore materna $A_{i} A_{i}$ deve possuir o alelo $A_{i}$ da árvore mãe; b) em casos de uma árvore mãe heterozigota $\left.\left(\operatorname{ex} . A_{i} A_{j}, i \neq j\right): i\right)$ cada indivíduo de uma progênie deve possuir um dos alelos da árvore materna, $A_{i}$ ou $A_{j}$. ii) o número de progênies heterozigotas $A_{i} A_{j}\left(N_{i j}\right)$ é esperado ser igual a soma das progênies homozigotas $A_{i} A_{i}\left(N_{i i}\right)$ $A_{j} A_{j}\left(N_{j j}\right), N_{i j}=N_{i i}+N_{j j}$; iii) o número de progênies heterozigotas $A_{i} A_{k}\left(N_{i k}\right)$ é esperado ser igual ao número de progênies heterozigotas $A_{j} A_{k}\left(N_{j k}\right), N_{i k}=N_{j k}$, com $k \neq i, j$. A análise genética foi realizada com 20 plantas de cada uma das 20 progênies de polinização aberta.

Os fenótipos observados em cada progênie das árvores maternas heterozigotas foram comparados com o esperado pela hipótese de segregação 1:1. As hipóteses foram aceitas ou descartadas com base em um teste G. Os fenótipos observados em progênies das árvores heterozigotas do mesmo genótipo materno foram somados e um teste $\mathrm{G}$

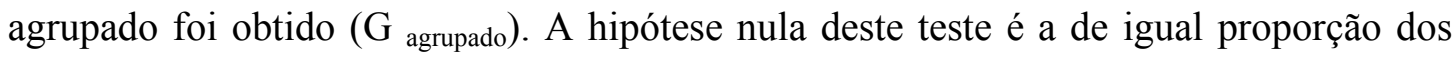


tipos de gametas em progênie produzida por diferentes árvores maternas de mesmo genótipo heterozigoto. Após isso, testou-se a hipótese de heterogeneidade de segregação entre progênies, usando-se um teste $G$ de heterogeneidade $\left(G_{\text {heterogeneidade }}\right)$, obtido pela subtração do teste $G\left(G_{\text {agrupado }}\right)$ da soma dos testes $G$ individuais por progênies.

O teste de desequilíbrio de ligação foi realizado com base na medida composta de desequilíbrio de ligação de Burrows $\left(\Delta_{i j}\right)$ Weir, 1979), usando o programa POPGENE versão 1.32 (Yeh et al., 1999). A medida de desequilíbrio de ligação de Burrows é apropriada para situações onde a união de gametas não ocorreu de forma aleatória e a identificação dos genótipos é incompleta (Weir \& Cockerham, 1979). A hipótese $\mathrm{H}_{0}: \Delta_{i j}=0$ foi testada com o teste de qui-quadrado $\left(\chi^{2}\right)$ descrito em Weir (1979). Os locos foram designados com letras e números e os alelos com números, em ordem decrescente de migração do anodo para o catodo.

\subsubsection{Variabilidade genética}

\subsubsection{Freqüências alélicas}

As freqüências alélicas foram estimadas pelo programa GDA utilizando a seguinte expressão:

$$
\hat{p}_{i j}=n_{i j} / n_{. j}
$$

onde: $\hat{p}_{i j}=$ estimativa da freqüência do alelo $i$ na população $j ; n_{i j}=$ número de ocorrências do alelo i na amostra da população $j ; n_{\cdot j}=$ número total de alelos encontrados na amostra da população $j$.

\subsubsection{Proporção de locos polimórficos $(\hat{P})$}

A proporção de locos polimórficos $(\hat{P})$ foi obtida considerando-se os locos que apresentaram a freqüência igual ou menor do que $95 \%$ do alelo mais freqüente. 


\subsubsection{Número médio de alelos por loco $(\hat{A})$}

$\mathrm{O}$ número médio de alelos por loco exprime a riqueza alélica presente na população e foi calculado para cada loco por:

$$
\hat{A}_{e}=\frac{1}{\sum \hat{p}_{i}^{2}}
$$

em que $\mathrm{p}_{i}$ é a freqüência alélica do alelo $i$

\subsubsection{Heterozigosidade média observada $\left(\hat{H}_{o}\right)$}

A heterozigosidade média observada $\left(\hat{H}_{o}\right)$ foi obtida pela média do número de genótipos heterozigotos em relação ao total de genótipos em cada loco e para as médias dos locos de acordo com a equação abaixo:

$$
\begin{aligned}
& \hat{H}_{o}=1-\sum_{i} \hat{p} i i \\
& \widetilde{H}_{o}=\frac{1}{m} \sum^{m} \widetilde{H}
\end{aligned}
$$

em que, $m$ é número de locos e $H$ é a heterozigosidade observada em cada loco.

\subsubsection{Heterozigosidade média esperada $\left(\hat{H}_{e}\right)$}

A heterozigosidade esperada $\left(\hat{H}_{e}\right)$ foi estimada pela média das $\hat{H}_{e}$ nos locos de acordo com a seguinte expressão:

$$
\begin{gathered}
\hat{H}_{e}=1-\sum_{i=1}^{k}{\widetilde{p}_{i}}^{2} \\
\hat{H}_{e}=1-\sum_{i} \sum_{j}^{m} p_{i j}^{2} / m
\end{gathered}
$$

onde: $n=$ número de indivíduos e $p_{i}$ é a freqüência do iésimo alelo.

\subsubsection{6 Índice de fixação de Wright $(\hat{f})$}

Este índice mede a fração de redução na heterozigosidade com relação ao esperado em uma população de cruzamentos aleatórios, conforme as expectativas do 
Equilíbrio de Hardy-Weinberg. Quanto mais próximos de zero os índices, maior é a panmixia, ou seja, a população está em EHW.

O índice de fixação $\hat{f}$ nas árvores adultas foi obtidos segundo Weir (1996),

$$
\hat{F}_{p}=\frac{\left(\hat{H}_{e}-\hat{H}_{o}\right)+\frac{1}{2 n} \hat{H}_{o}}{\hat{H}_{e}-\frac{1}{2 n} \hat{H}_{o}} .
$$

onde: $\hat{H}_{e}$ é a heterozigosidade esperada em EHW e $\hat{H}_{o}$ é heterozigosidade observada. A significância estatística de $\hat{f}$ foi calculada pelo intervalo de confiança a $95 \%$ de probabilidade sendo estimados por método de reamostragem bootstrap, usando 10.000 repetições sobre os locos e o programa GDA (Lewis \& Zaykin, 1999).

\subsubsection{Tamanho efetivo $\left(\hat{N}_{e}\right)$}

Para o cálculo do tamanho efetivo de endogamia $\left(\hat{N}_{e}\right)$ utilizou-se a seguinte expressão:

$$
\hat{N}_{e}=n /(1+\hat{f})
$$

$n$ é o número de indivíduos adultos amostrados $\hat{f}=$ coeficiente de endogamia intrapopulacional

\subsubsection{Sistema de reprodução}

O sistema de reprodução foi analisado com base nos modelos de reprodução mista (Ritland \& Jain 1981) e cruzamentos correlacionados (Ritland 1989), usando o programa "Multilocos MLTR" (Ritland 2002). As pressuposições do modelo misto são dadas em Ritland \& Jain (1981). Os parâmetros estimados foram: taxa populacional de cruzamento multiloco $\left(\nexists_{m}\right)$; taxa populacional de cruzamento uniloco $\left(\bar{E}_{s}\right)$; taxa de cruzamento entre aparentados $\left(1-\nexists_{s}\right)$; correlação multilocos de paternidade $\left(\hat{r}_{p(m)}\right)$, correlação unilocos de paternidade $\left(\hat{r}_{p(s)}\right)$, donde derivam-se a proporção de irmãos- 
completos $\left(\hat{r}_{p}\right)$ e meios-irmãos $\left(1-\hat{r}_{p}\right)$. Foram também estimadas as freqüências alélicas do pólen e óvulos cruzados. O erro padrão das estimativas dos parâmetros foi obtido por meio de 500 reamostragens bootstraps.

O teste de cruzamentos aleatórios foi realizado pelo teste de homogeneidade das freqüências alélicas dos óvulos e do pólen, usando a estatística $F_{S T}$ (Wright, 1965). A significância de $F_{S T}$, para cada loco, foi obtida pelo teste de qui-quadrado $\left[\chi^{2}=2 n F_{S T}(k-1), \mathrm{GL}=(\mathrm{K}-1)(\mathrm{s}-1)\right]$, proposto por Workman \& Niswander (1970), sendo $n$ o número de gametas nos dois grupos (pólen e óvulos), $k$ é o número de alelos e $s$ é o número de grupos. A significância estatística dos valores médio entre locos para $F_{S T}$ foi obtida por reamostragem Jackknife (Sokal \& Rolf, 1981).

Tais análises foram também usadas para verificar se as freqüências alélicas dos óvulos diferiam das árvores femininas, se as freqüências alélicas do pólen cruzado diferiam das freqüências alélicas das árvores masculinas e se as freqüências alélicas das árvores masculinas diferiam das árvores femininas.

O coeficiente de coancestria $\left(\hat{\theta}_{x y}\right)$ entre plantas dentro de progênies foi estimado a partir do coeficiente de parentesco $\left(\nabla_{x y}\right)$ entre plantas dentro de progênies, conforme derivação de Ritland (1989),

$$
r_{x y}=0,25(1+\hat{F})\left(4 \hat{s}+\left(\hat{t}+\hat{s} \hat{t} \hat{r}_{s}\right)\left(1+\hat{r}_{p}\right)\right]
$$

em que, $\hat{F}$ é o coeficiente de endogamia na geração parental e $\hat{s}$ é a estimativa da taxa de autofecundação $\left(1-\partial_{m}\right)$. Assumindo ausência de parentesco e endogamia na geração parental, o coeficiente de coancestria pode ser estimado do coeficiente de parentesco por $\hat{\theta}_{x y}=\hat{r}_{x y} / 2$. 
O número provável de doadores de pólen $\left(\hat{N}_{e p}\right)$ foi estimado da correlação de paternidade por, $\hat{N}_{e p}=1 / \hat{r}_{p}$. Da correlação de paternidade estimou-se também a divergência genética entre o pólen cruzado, a partir da relação,

$$
\begin{gathered}
1 / \hat{r}_{p}=1 / 2 \hat{\Phi}_{f t} \\
\hat{\Phi}_{f t}=\hat{r}_{p} / 2
\end{gathered}
$$

Para conhecer a representatividade genética das progênies foi estimado o tamanho efetivo de variância $\left(\hat{N}_{e(v)}\right)$ de uma progênie com base na variância amostral das freqüências alélicas (Cockerham, 1969) e utilizando uma população idealizada como referência (Sebbenn, 2002),

$$
\hat{N}_{e(v)}=\frac{0,5}{\hat{\theta}_{x y}\left(\frac{n-1}{n}\right)+\frac{1+\hat{F}_{p}}{2 n}} .
$$

\subsubsection{Estrutura espacial dos genótipos}

O coeficiente de coancestria $\left(\hat{\theta}_{x y}\right)$ entre pares de árvores foi estimado para 12 classes de distância iguais de 50 metros, usando o coeficiente de coancestria proposto por Loiselle et al. (1995), que é definido para cada $k$ alelo em cada par de indivíduos, $x$ e $y$, como,

$$
\hat{\theta}_{x y}=\frac{\left(p_{x}-\bar{p}_{k}\right)\left(p_{y}-\bar{p}_{k}\right)}{\bar{p}_{k}\left(1-\bar{p}_{k}\right)}+\frac{1}{2 n-1}
$$

em que, $p_{x}$ e $p_{y}$ são as freqüências do alelo $k$ nos indivíduos $x$ e $y$ (assumindo valores de $0,0,5$ e 1 em indivíduos homozigotos para o alelo alternativo, heterozigotos e homozigotos para o alelo sob consideração, respectivamente) e $\bar{p}_{k}$ é a média da freqüência do alelo $k$ na subpopulação como tamanho amostral $n$. As estimativas média multilocos foram calculadas pela ponderação de $\hat{\theta}_{x y}$ em função do índice de polimorfismo de cada alelo $k \quad \bar{p}_{k}\left(1-\bar{p}_{k}\right)$. O intervalo de confiança a $95 \%$ de probabilidade do coeficiente médio de coancestria estimado para cada classe de distância 
foi construído com base no erro padrão da média das estimativas, obtido por reamostragem jackknifed entre locos. O coeficiente de coancestria e o erro padrão foram estimados usando o programa SPAGeDi versão 1.1 (Hardy e Vekemans, 2003). 


\section{RESULTADOS E DISCUSSÃO}

\subsection{Herança genética e desequilíbrio de ligação}

Umas das pressuposições básicas do modelo de reprodução mista é a independência na segregação de alelos de diferentes locos. Assim serão apresentados os padrões dos locos isoenzimáticos e os resultados dos testes de segregação e desequilíbrio gamético que são desejáveis nos estudo de sistema de reprodução.

\subsubsection{Padrões dos locos isoenzimáticos polimórficos}

Alfa-Esterase ( $\alpha$-EST)

O sistema $\alpha$-EST apresentou uma região de atividade isoenzimática interpretada como um loco polimórfico com três alelos.

Fosfoglucose Isomerase (PGI)

O sistema PGI apresentou uma zona de atividade interpretada como um loco polimórfico, controlado por uma enzima de expressão dimérica, segregando dois alelos. Fosfatase ácida (ACP)

A zona de atividade foi interpretada como uma enzima de expressão monomérica, visto que a observação de genótipos heterozigotos nos zimogramas revelava duas bandas.

Diaforase (DIA)

O sistema DIA apresentou uma zona de atividade. Esta zona foi interpretada como loco polimórfico de expressão monomérica, segregando dois alelos.

\section{Glucose 6 Fosfato Desidrogenase (G6PDH)}

Uma simples zona de atividade foi observada na enzima G6PDH. Esse loco foi interpretado como polimórfico, segregando dois alelos em estrutura monomérica. Um simples loco controlando essa enzima também foi relatado em Pinus thunbergii Parl 
(Shiraishi, 1988), Pinus leucodermis Ant. (Morgante et al., 1993) e Pinus massoniana Lamb (Huang et al., 1994). Observando os zimogramas nos géis de indivíduos heterozigotos, verificou-se que o fenótipo isoenzimático apresentava duas bandas, típico de enzimas monoméricas.

Fosfogluconato Desidrogenase (6-PGDH)

Uma simples zona foi detectada na enzima 6PGDH. A observação de fenótipos de indivíduos heterozigotos indicou que esta enzima tem expressão monomérica e segrega 2 alelos. Um simples loco no sistema 6PGDPH também foi relatado em P. taeda (Adams \& Joly, 1980) e C. legalis (Sebbenn et al., 2004), embora em muitos estudos dois locos tenham sido reportados nessa enzima (Cheliak \& Pitel, 1985; Potenko, 2001; Sousa et al., 2002).

Fosfoglucomutase (PGM)

O sistema apresentou uma zona de atividade. Este loco foi interpretado como polimórfico segregando 3 alelos em estrutura monomérica.

\section{Zimogramas}
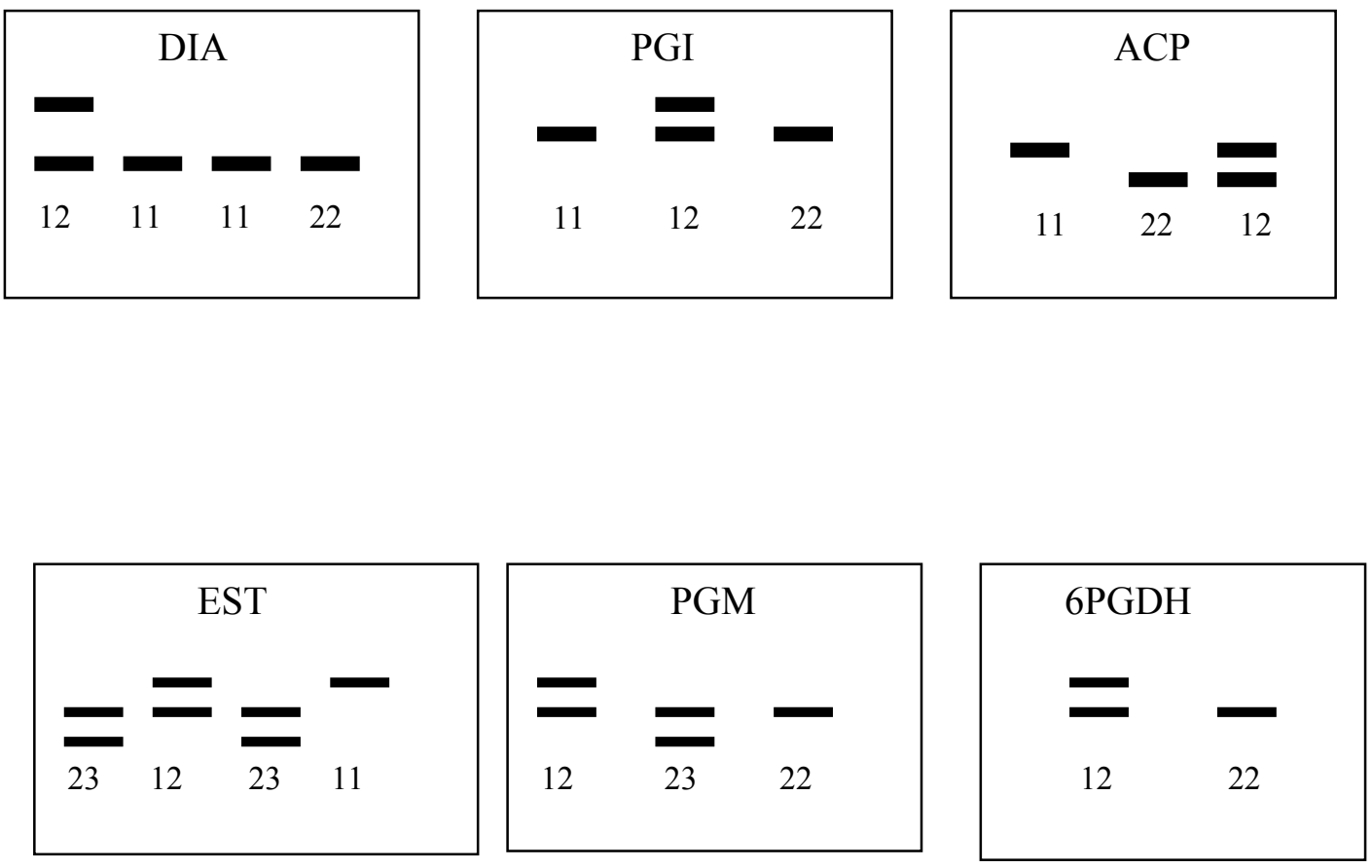

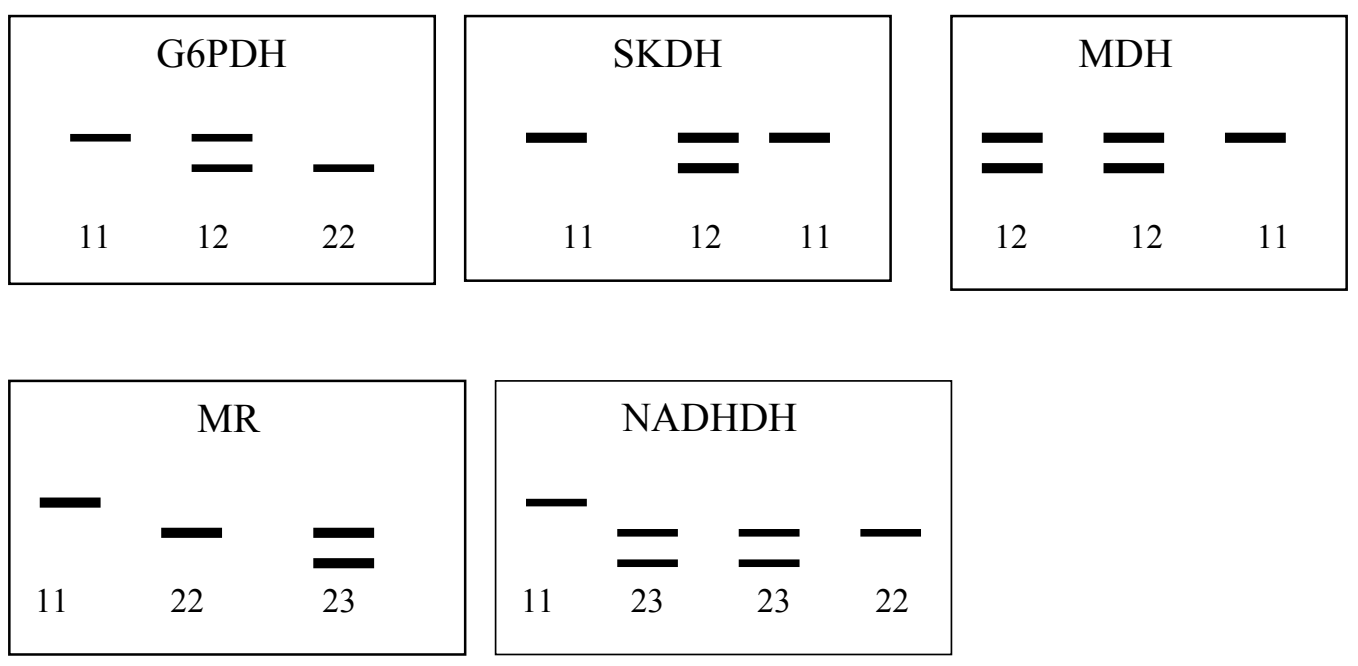

Figura 1 - Representação esquemática da interpretação de bandas dos sistemas enzimáticos analisados para a população de Eremanthus erythropappus em Baependi - MG

\subsubsection{Segregação}

Não foram detectados fortes indícios de desvios de segregação nos locos isoenzimáticos estudados em progênies de Eremanthus erythropappus (Tabela 3).Da mesma forma, não foram detectados desvios da razão de segregação esperada 1:1 em progênies de árvores heterozigotas nos locos Acp, Dia e Est. Já para progênies de árvores heterozigotas $A_{1} A_{3}$ e $A_{2} A_{3}$ para o loco Est, foram detectados desvios. No entanto, quando foram excluídas progênies com desvio, o loco ajustou-se à hipótese de segregação 1:1. A análise genética de progênies de árvores heterozigotas $A_{1} A_{2}$, para o loco 6Pgdh rejeitou a hipótese de segregação 1:1 nos testes Gtotal, Gheterogeneidade e Gagrupado. No entanto, quando progênies de árvores heterozigotas com desvios foram excluídas das análises, o loco ajustou-se à hipótese de segregação mendeliana. O teste Gagrupado para o loco Pgi foi não significativo, ajustando-se à hipótese de segregação 1:1. No entanto, para os outros dois testes foi significativo, não ajustando-se a hipótese. Quando progênies de árvores heterozigotas com desvios foram excluídas das análises o 
loco ajustou-se perfeitamente à hipótese. Embora o teste Gagrupado tenha sido significativo, aceita-se à hipótese de segregação 1:1 para o loco Pgi em virtude dos outros dois testes terem sido não significativos.

Tabela 3. Teste para hipótese de segregação $G$ de marcadores isoenzimáticos em população de Eremanthus erythropappus em Baependi - MG

\begin{tabular}{ccccccccc}
\hline Loco & $\begin{array}{c}\text { Genótipo } \\
\text { Materno }\end{array}$ & Caso & $N$ & $N_{i j}$ & $N_{i i}+N_{j j}$ & $\mathrm{G}_{\text {Total }}$ & $\mathrm{G}_{\text {Heterogeneidade }}$ & $\mathrm{G}_{\text {Agrupado }}$ \\
\hline Acp & $A_{1} A_{2}$ & $\mathrm{a}$ & 24 & 117 & 128 & $24,8 \mathrm{~ns}$ & $24,3 \mathrm{~ns}$ & $0,49 \mathrm{~ns}$ \\
Est & $A_{1} A_{2}$ & a & 16 & 73 & 67 & $19,01 \mathrm{~ns}$ & $18,75 \mathrm{~ns}$ & $0,25 \mathrm{~ns}$ \\
& $A_{1} A_{3}$ & a & 4 & 12 & 22 & $28,52^{* *}$ & $21,35^{* *}$ & $7,17^{*}$ \\
& & b & 2 & 3 & 8 & $3,56 \mathrm{~ns}$ & $1,00 \mathrm{~ns}$ & $2,56 \mathrm{~ns}$ \\
& $A_{2} A_{3}$ & a & 3 & 3 & 5 & $11,7 \mathrm{~ns}$ & $4,53 \mathrm{~ns}$ & $7,24^{*}$ \\
& & b & 2 & 3 & 4 & $4,84 \mathrm{~ns}$ & $2,34 \mathrm{~ns}$ & $2,50 \mathrm{~ns}$ \\
6Pgdh & $A_{1} A_{2}$ & a & 30 & 204 & 132 & $63,14^{* *}$ & $47,59^{*}$ & $15,55^{* *}$ \\
& & b & 21 & 128 & 102 & $16,7 \mathrm{~ns}$ & $13,76 \mathrm{~ns}$ & $2,95 \mathrm{~ns}$ \\
Pgm & $A_{1} A_{2}$ & a & 6 & 22 & 44 & $12,4 \mathrm{~ns}$ & $5 \mathrm{~ns}$ & $7,48^{* *}$ \\
Pgi & $A_{1} A_{2}$ & a & 13 & 81 & 66 & $56,97^{* *}$ & $55,44^{* *}$ & $1,53 \mathrm{~ns}$ \\
& & b & 8 & 39 & 41 & $8,17 \mathrm{~ns}$ & $8,12 \mathrm{~ns}$ & $0,05 \mathrm{~ns}$ \\
Dia & $A_{1} A_{2}$ & a & 20 & 95 & 75 & $29,5 \mathrm{~ns}$ & $27,18 \mathrm{~ns}$ & $2,36 \mathrm{~ns}$ \\
& & & & & & & & \\
\hline
\end{tabular}

$\overline{N_{i j}}$ e $N_{i i}+N_{j j}$ são os números observados dos genótipos heterozigotos e homozigotos, respectivamente; $N_{i k}$ e $N_{j k}$ são os números observados dos genótipos heterozigotos do tipo $i k$ e $j k$, respectivamente;

**: $P<0,010 ; *: P<0,050 ;$ ns= não significativo.

Desvios de segregação têm sido detectados em vários locos isoenzimáticos de espécies arbóreas (Cheliak \& Pitel, 1985; Shiraishi, 1988; Konnert et al., 2001; Sousa et al., 2002). Diversas podem ser as causas dos desvios de segregação observados no loco Pgm; estas podem ser: isoenzimas podem estar sob controle de mais de um loco, seleção, distorções meióticas, interações interalélicas, ligação com locos, possuindo alelos deletérios, erro amostral e erros de interpretação dos zimogramas nos géis (Cheliak \& Pitel, 1985; Strauss \& Conkle, 1986). 


\subsubsection{Desequilíbrio gamético}

O teste de desequilíbrio gamético foi realizado usando-se os locos polimórficos com base na medida composta de desequilíbrio gamético de Burrows. (Tabela 4). Dos 21 pares possíveis de combinações entre locos avaliando-se os adultos, as progênies antes do manejo e pós manejo, só foram detectados indícios significativos de desequilíbrio de ligação os pares (Acp/Pgi; Est/Acp; G6pdh/6pgdh; Dia/Pgi) entre adultos, (G6pdh/Pgi; G6pdh/6pgdh e Acp/6pgdh) nas progênies antes do manejo e (Acp/6pgdh; G6pdh/Pgi; 6pgdh/Dia; Acp/Est) nas progênies pós manejo. Isto indica que os alelos desses locos estão associados e não segregam independentemente, de forma que um dos locos deve ser removido de análises que requeiram locos em equilíbrio gamético, como estudos do sistema de reprodução, análise de paternidade e estrutura genética populacional. Nos demais pares de locos não foram detectados indícios de desequilíbrio gamético e é possível afirmar que os alelos de diferentes locos não estão associados e segregam independentemente.

Tabela 4. Valores da medida composta de Burrows para o desequilíbrio gamético $\left(\hat{\Delta}_{i j}\right)$, resultados do teste de qui-quadrado $\left(X^{2}\right)$ para pares de locos isoenzimáticos que apresentaram desvios significativos da hipótese de desequilíbrio gamético em população de Eremanthus erythropappus em Baependi - MG

\begin{tabular}{lcccccc}
\hline \multirow{2}{*}{ Pares de locos } & $\hat{\Delta}_{i j}$ & $X^{2}$ & $\hat{\Delta}_{i j}$ & $X^{2}$ & $\hat{\Delta}_{i j}$ & $X^{2}$ \\
\hline Acp/Pgi & $-0,045$ & $4,38^{*}$ & 0,005 & 0,32 & $-0,0016$ & 0,011 \\
Acp/Pgm & 0,023 & 0,89 & - & - & - & - \\
Acp/6pgdh & 0,005 & 0,094 & 0,030 & $5,03^{*}$ & $-0,019$ & $3,94^{*}$ \\
Acp/G6pdh & 0,012 & 0,57 & 0,004 & 0,49 & 0,0004 & 0,0018 \\
Acp/Dia & 0,004 & 0,036 & - & - & $-0,0003$ & 0,0006 \\
Est/Pgi & $-0,005$ & 0,06 & 0,014 & 1,69 & 0,010 & 0,24 \\
Est/Pgm & 0,006 & 0,06 & - & - & - & - \\
Est/6pgdh & 0,012 & 0,49 & 0,026 & 3,39 & $-0,005$ & 0,157 \\
Est/G6pdh & 0,003 & 0,024 & 0,013 & 3,43 & 0,001 & 0,074 \\
Est/Dia & $-0,035$ & 2,74 & - & - & 0,019 & 0,87 \\
Est/Acp & 0,066 & $8,77^{*}$ & 0,024 & 2,02 & 0,0309 & $4,257^{*}$ \\
6Pgdh/Pgi & $-0,010$ & 0,49 & $-0,0027$ & 0,15 & 0,005 & 0,22 \\
6pgdh/Pgm & 0,009 & 0,34 & - & - & - & - \\
G6pdh/Pgi & $-0,018$ & 1,05 & $-0,0098$ & $4,53^{*}$ & $-0,026$ & $4,88^{*}$ \\
G6pdh/Pgm & 0,011 & 0,311 & - & - & - & -
\end{tabular}


Tabela 4. Valores da medida composta de Burrows para o desequilíbrio gamético $\left(\hat{\Delta}_{i j}\right)$, resultados do teste de qui-quadrado $\left(X^{2}\right)$ para pares de locos isoenzimáticos que apresentaram desvios significativos da hipótese de desequilíbrio gamético em população de Eremanthus erythropappus em Baependi - MG

\begin{tabular}{lcccccc}
\hline G6pdh/6pgdh & 0,027 & $5,14^{*}$ & $-0,013$ & $5,83^{*}$ & $-0,004$ & 0,22 \\
Dia/Pgi & 0,063 & $10,65^{* *}$ & - & - & - & - \\
Dia/Pgm & $-0,017$ & 0,61 & - & - & $-0,002$ & 0,014 \\
Dia/6Pgdh & 0,001 & 0,00 & - & - & 0,031 & $6,21^{*}$ \\
Dia/G6pdh & $-0,085$ & 17,45 & - & - & 0,002 & 0,023 \\
Pgm/Pgi & $-0,012$ & 0,38 & - & - & - & - \\
\hline${ }^{* *} P<0,010 ;{ }^{*} P<0,050$. & & & & & &
\end{tabular}

\subsection{Variabilidade genética}

Dos 13 locos avaliados, dois eram monomórficos como pode ser observado na (Tabela 5), os demais apresentaram de dois a três alelos. No total, foram detectados 30 alelos, sendo seis $(20 \%)$ alelos de baixa freqüência e três $(10 \%)$ alelos raros. Não foram detectados alelos muito raros na amostra, embora o tamanho amostral adotado (213) apresentasse potencial para detectar tais alelos (a probabilidade de detectar pelo menos um alelo com freqüência 0,01 , quando 213 indivíduos são amostrados é $\left.0,989=\hat{P}=1-(1-p)^{2 n}\right)$, sugerindo ausência de alelos muito raros na população ou erro amostral).

Os demais locos apresentaram distribuição igualitária das freqüências dos alelos, com exceção dos locos G6pdh e $M d h$, que apresentaram um alelo com freqüência alta $(>0,75)$ nos adultos. Nas progênies antes do manejo dois locos apresentaram freqüência alta (G6pdh e Pgi) e nas progênies após manejo (Acp e G6pdh).

O número de alelos por loco (Tabela 6) é considerado alto $(2,30)$ comparando-se com valores encontrados por Pereira (2002) em Miconia cinnamomifolia $(2,14)$ e Gusson (2003) em Eschweilera ovata $(2,14)$. Nas progênies este valor foi superior $(2,57)$ o que também foi observado por Gusson (2003). Gusson (2003) também observou maior número de alelos nas progênies relativamente à geração adulta. Este resultado sugere que o tamanho da população reprodutiva é maior do que o da população adulta amostrada.

A porcentagem de locos polimórficos $(76,92 \%)$ é superior a estimativa de $50 \%$ de locos polimórficos para espécies vegetais encontrada por Hamrick \& Godt (1990) 
podendo-se concluir que a espécie apresenta alto polimorfismo. Também em comparação com as espécies arbóreas apresentadas na Tabela 7, para a porcentagem de locos polimórficos o valor encontrado para população de Eremanthus erythropappus pode ser considerado alto. Nas progênies após manejo analisadas todos os locos analisados foram polimórficos (100\%).

Tabela 5. Estimativa de freqüências alélicas em população de Eremanthus erythropappus em Baependi - MG

\begin{tabular}{|c|c|c|c|c|}
\hline \multirow[b]{3}{*}{ Loco } & \multirow[b]{3}{*}{ Alelo } & \multirow[t]{3}{*}{ Adulto } & \multicolumn{2}{|c|}{ Progênie } \\
\hline & & & Antes Manejo & Pós Manejo \\
\hline & & & & \\
\hline \multirow[t]{3}{*}{ Est } & 1 & 0,357 & 0,5063 & 0,4515 \\
\hline & 2 & 0,469 & 0,3777 & 0,4119 \\
\hline & 3 & 0,173 & 0,1158 & 0,1365 \\
\hline \multirow[t]{3}{*}{ Acp } & 1 & 0,537 & 0,3858 & 0,2004 \\
\hline & 2 & 0,417 & 0,5896 & 0,7995 \\
\hline & 3 & 0,045 & 0,0231 & - \\
\hline \multirow[t]{3}{*}{ Dia } & 1 & 0,397 & 0,3391 & 0,4353 \\
\hline & 2 & 0,435 & 0,6608 & 0,5646 \\
\hline & 3 & 0,166 & - & - \\
\hline \multirow[t]{3}{*}{ G6pdh } & 1 & 0,868 & 0,9621 & 0,9057 \\
\hline & 2 & 0,131 & 0,0379 & 0,063 \\
\hline & 3 & & - & 0,0308 \\
\hline \multirow[t]{2}{*}{ 6pgdh } & 1 & 0,246 & 0,3812 & 0,2848 \\
\hline & 2 & 0,753 & 0,6188 & 0,7151 \\
\hline \multirow[t]{3}{*}{ Pgm } & 1 & 0,381 & 0,5685 & 0,4351 \\
\hline & 2 & 0,600 & 0,4285 & 0,5555 \\
\hline & 3 & 0,019 & 0,0028 & 0,0092 \\
\hline \multirow[t]{3}{*}{ Pgi } & 1 & 0,468 & 0,8608 & 0,6532 \\
\hline & 2 & 0,531 & 0,1391 & 0,3306 \\
\hline & 3 & - & - & 0,0161 \\
\hline \multirow[t]{2}{*}{ Skdh } & 1 & 0,613 & - & - \\
\hline & 2 & 0,386 & - & - \\
\hline \multirow{3}{*}{ Nadhdh } & 1 & 0,396 & - & - \\
\hline & 2 & 0,405 & - & - \\
\hline & 3 & 0,198 & - & - \\
\hline \multirow[t]{2}{*}{ Mdh } & 1 & 0,954 & - & - \\
\hline & 2 & 0,045 & - & - \\
\hline \multirow[t]{3}{*}{$\mathrm{Mr}$} & 1 & 0,413 & - & - \\
\hline & 2 & 0,453 & - & - \\
\hline & 3 & 0,132 & - & - \\
\hline Got & 1 & 1 & - & - \\
\hline Lap & 1 & 1 & - & - \\
\hline Total de alelos & 30 & & 17 & 18 \\
\hline Alelos de baixa freq.: $0,25 \geq p<0,05$ & & $6(20 \%)$ & $2(11,76 \%)$ & $3(16,66 \%)$ \\
\hline Alelos raros: $0,05 \geq p<0,01$ & & $3(10 \%)$ & $2(11,76 \%)$ & $2(11,11 \%)$ \\
\hline Alelos muito raros: $p<0,01$ & & 0 & $1(5,8 \%)$ & $1(5,55 \%)$ \\
\hline
\end{tabular}


A heterozigosidade esperada segundo as expectativas de EHW variou de 0,399 nos adultos a 0,425 nas progênies após manejo e a heterozigosidade observada variou de 0,299 a 0,423 nas progênies após manejo. Ambas podem ser consideradas altas consideradas altas quando comparada com outras espécies arbóreas tropicais citadas na Tabela 7.

Tabela 6. Índices de diversidade genética intrapopulacional em árvores adultas de uma população de Eremanthus erythropappus em Baependi - MG

\begin{tabular}{|c|c|c|c|}
\hline \multirow[t]{2}{*}{ Índices } & \multirow[t]{2}{*}{ Adultos } & \multicolumn{2}{|c|}{ Progênies } \\
\hline & & Antes do manejo & Após o manejo \\
\hline$N$ & 189,5 & 308 & 219 \\
\hline$\hat{A}$ & 2,30 & 2,57 & 2,57 \\
\hline$\hat{P}$ & $76,92 \%$ & $86 \%$ & $100 \%$ \\
\hline$\hat{H}_{o}$ & 0,299 & 0,357 & 0,423 \\
\hline$\hat{H}_{e}$ & 0,399 & 0,403 & 0,425 \\
\hline$\hat{N}_{e}$ & 178,4 & - & - \\
\hline
\end{tabular}

A heterozigosidade observada nos adultos e nas progênies antes do manejo foi menor que a esperada, indicando que há mais homozigotos na população do que o esperado pelas proporções de EHW. O mesmo resultado pode ser observado e confirmado no alto e significativo índice de fixação $(0,25)$ (Tabela 9). O índice de fixação mede o excesso ou a deficiência de heterozigotos em relação ao esperado em uma população panmítica, ou seja, quando o valor é igual a zero, a população está ajustada às proporções do Equilíbrio de Hardy-Weinberg e quando os valores são significativamente maiores ou menores que zero, indica que há um excesso de homozigotos ou de heterozigotos, respectivamente. Os atos níveis de heterozigosidade sugerem que a espécie é, provavelmente, de cruzamentos e o alto excesso de homozigotos indica que a espécie pratica alguma forma de endogamia como autofecundações e cruzamentos entre parentes. Estes aspectos serão mais explorados na 
análise do sistema de reprodução, mas em suma tal resultado permite supor que a espécie é de sistema misto de reprodução, combinando autofecundações com predomínio de cruzamentos.

A heterozigosidade observada e esperada nas progênies após o manejo apresentaram valores muito próximos $\left(\hat{H}_{o}=0,423 ; \hat{H}_{e}=0,425\right)$, indicando que a população está ajustada as proporções do EHW. Fato confirmado pelo índice de fixação não significativo próximo e não significativamente diferente de zero $(0,05)$.

Foi anteriormente ressaltado que a diversidade genética nas progênies antes do manejo foi maior do que a observada na geração adulta, indicando que o tamanho reprodutivo da população era maior do que o tamanho genético da população adulta amostrada. Adicionalmente, comparando os índice de diversidade genética nas progênies antes e após o manejo, verifica-se que os índices aumentaram após a exploração, isto é, o tamanho da população reprodutiva ficou maior ainda. O aumento no tamanho reprodutivo da população pode ter ocorrido devido à exploração reduzir a densidade vegetal, favorecendo assim, o movimento dos polinizadores, resultado em maiores níveis de diversidade genética. Existem algumas evidências de que certas taxas de exploração possam alterar o comportamento dos polinizadores e, portanto, o sistema de reprodução White et al. (2002) detectaram na espécie arbórea tropical Swietenia humillis, que alguns fragmentos recebiam grande contribuição de pólen vindo de mais de 4,5 km de distância, interpretando estes resultados como um fator positivo da fragmentação que teria favorecido a longa distância de polinização pela abertura de espaço, favorecendo o vôo dos polinizadores. Aldrich \& Hamrick (1998) observaram que muitas das sementes produzidas dentro de fragmentos de Symphonia globulifera eram o resultado da contribuição de pólen de árvores isoladas localizadas em pastagens a centenas de metros dos fragmentos, embora também detectaram que muitas sementes produzidas nos fragmentos foram resultantes da contribuição polínica de poucas árvores polinizadoras, $o$ que reflete a presença de deriva genética no processo de reprodução como um resultado da fragmentação da paisagem. Em suma, o aumento do tamanho da população não obrigatoriamente reflete um grande tamanho de vizinhança genética. 
Os altos níveis de diversidade genética detectados na espécie em termos de porcentagem de locos polimórficos, número médio de alelos e heterozigosidades podem ser atribuídos às suas características demográficas como alta densidade populacional e ocorrência em ambientes extremos (locais montanhosos, terrenos rochosos e solos de baixa qualidade). A estimativa do tamanho efetivo de endogamia $(178,4)$ foi menor do que o número senso (213), resultando na relação $\hat{N}_{e} / n$ de 0,78 . Ressalta-se, contudo, que embora o tamanho efetivo de endogamia seja menor do que o número senso ele indica que a população em estudo apresenta alto potencial genético para a conservação genética e manutenção dos níveis de diversidade genética por pelo menos 10 gerações $\left(\hat{N}_{e}>50\right)$. A alta representatividade genética foi compensada pelo grande tamanho da população.

Em suma, as características genética e demográfica da população estudada de Eremanthus erythropappus permitem supor que a mesma tem potencial para a exploração florestal e que se a intensidade de exploração não for muito drástica, a população poderá ser manejada. Contudo, são necessários estudos baseados e modelagem e simulação de longo prazo para se fazer afirmações mais fortes sobre este assunto.

Tabela 7. Estudos genéticos por marcadores com algumas espécies arbóreas da Mata Atlântica - Brasil, em que: $\hat{A}=\mathrm{n}^{\mathrm{o}}$. de alelos por loco; $\hat{P}=$ polimorfismo (\%); $\hat{H}_{e}=$ diversidade gênica e $\hat{H}_{o}=$ heterozigosidade observada

\begin{tabular}{lcccc}
\hline \multicolumn{1}{c}{ Espécie } & $\hat{P}$ & $\hat{A}$ & $\hat{H}_{o}$ & $\hat{H}_{e}$ \\
\hline Aspidosperma polyneuron (1) & 50,0 & 8 & 0,236 & 0,243 \\
Bauhinia forficata (2) & 100,0 & 4 & 0,451 & 0,503 \\
Chorisia speciosa (3) & 77,8 & 9 & 0,245 & 0,284 \\
Genipa americana (4) & 50,0 & 8 & 0,195 & 0,182 \\
Myracroduon urundeuva (5) & 66,7 & 3 & 0,150 & 0,358 \\
Cedrela fissilis (6) & 76,9 & 14 & 0,222 & 0,243 \\
Euterpe edulis (7) & 100,0 & 7 & 0,496 & 0,463 \\
Eschweilera ovata (8) & 85,7 & 2,14 & 0,371 & 0,420 \\
Tabebuia cassinoides (9) & 100,0 & 2,64 & 0,504 & 0,491 \\
Trema micrantha (10) & 100,0 & 2,2 & 0,406 & 0,381 \\
Cecropia pachystachya (10) & 100, & 2,2 & 0,346 & 0,345 \\
Esenbeckia leiocarpa (10) & 75,0 & 2,3 & 0,395 & 0,391 \\
\hline
\end{tabular}

Autores: 1 Maltez (1997); 2 Santos (1994); 3 Souza (1997); 4 Sebbenn (1997); 5 Moraes (1993); 6 Gandara (1996); 7 Reis(1996); 8 (Gusson,2003); 9 (Cavallari Neto, 2004); 10 Ribas (2004); 11 (Seoane et al, 2001). 


\subsection{Sistema de reprodução}

\subsubsection{Freqüências alélicas dos óvulos e pólen}

A estimativa da divergência genética entre as freqüências alélicas dos óvulos e do pólen revelou diferenças significativas para os locos 6pgdh, Pgi, Pgm, G6pdh, 6Pgdh e Pgi para as análises antes do manejo e nos locos Pgm, e Pgi nas análises pós manejo (Tabela 8), ou seja, $85,7 \%$ e $28,5 \%$ dos locos antes e pós manejo, respectivamente, não se adequaram ao modelo de acasalamento misto de reprodução Ritland e Jain (1981). Diferenças entre as freqüências alélicas do pólen e dos óvulos podem ser atribuídas a diferenças nas funções masculina e feminina das plantas, imigração de pólen de fora das populações amostradas, seleção entre o período de polinização e análise de isoenzimas, devido à amostragem não representativa das árvores maternas (Ritland \& Jain, 1981) e desvios de cruzamentos aleatórios causados por autofecundações, cruzamentos biparentais, cruzamentos endogâmicos (cruzamentos entre indivíduos aparentados) e variação na fenologia de florescimento.

A amostragem não representativa das árvores maternas, fluxo gênico externo a população e os desvios de cruzamentos são as mais prováveis causas para as diferenças detectadas em E. erythropappus, devido à amostra ser relativamente grande (foram coletadas sementes em pelo menos 24 árvores), a espécie ser hermafrodita (todas as plantas reprodutivas tem tanto função masculina como feminina) e os locos avaliados serem neutros (não sofrem seleção).

\subsubsection{Taxas de cruzamentos multiloco e uniloco, de cruzamento entre parentes e cruzamentos correlacionados}

A taxa de cruzamento foi alta, não estatisticamente diferente de um e similar na análise antes $(0,963)$ e pós manejo $(0,967)$ indicando que a espécie é de cruzamentos (Tabela 9). As altas taxas de cruzamento detectadas sugerem a presença de mecanismos de auto-incompatibilidade na espécie. Espécies arbóreas tropicais, em geral apresentam valores de cruzamento maior do que 0,800. A taxa de cruzamento estimada para outra espécie arbórea tropical de alta densidade populacional, Esenbeckia leiocarpa, foi maior que 0,925 (Seoane et al, 2001). Gusson (2003) estimou para Eschweilera ovata, uma 
espécie arbórea tropical também de alta densidade populacional, valores de 0,999 e 0,933 para taxa de cruzamento multiloco e uniloco em população natural e 0,985 e 0,912 em população explorada, respectivamente. Portanto, observa-se que a população de Eremanthus erythropappus apresenta valores semelhantes ao detectado em outras espécies arbóreas tropicais de alta densidade, sugerindo que a probabilidade de ocorrerem grande número de recombinações e formação de ampla variedade de genótipos.

A taxa de cruzamento uniloco foi menor do que a taxa de cruzamento multiloco com valores de 0,914 e 0,933 antes e após manejo, respectivamente, sugerindo que ocorreram cruzamentos entre parentes. Estas estimativas, 3 e 5\%, foram significativamente diferentes de zero, de acordo com o intervalos de confiança do erro a 95\% de probabilidade. Em Esenbeckia leiocarpa o valor encontrado foi de 6\% (Seoane et al, 2001), em Genipa americana de 2\% (Sebbenn et al, 1998) e em Eschweilera ovata entre 6 e 7\% (Gusson, 2003). O cruzamento entre aparentados pode gerar endogamia biparental, apesar desse tipo de endogamia ser menos drástico do que a autofecundação efetiva (Allard, 1971).

As estimativas da correlação de autofecundação $\left(\hat{r}_{s}\right)$, ou a probabilidade de encontrar um indivíduo gerado por autofecundação onde foi encontrado outro indivíduo de autofecundações foram relativamente baixa, mas significativas nas duas populações $(0,188$ e 0,179$)$. Isso sugere que existe variação na taxa de cruzamento entre plantas individuais, portanto, embora a taxa de cruzamento multilocos tenha sido estatisticamente igual a unidade $(1,0)$, se existir auto-incompatibilidade na espécie, existe variação genética para auto-incompatibilidade e algumas plantas podem se autofecundar mais do que outras.

A correlação de paternidade $\left(\hat{r}_{p(s)}\right)$ mede a proporção de indivíduos de cruzamentos que foram gerados por cruzamentos biparentais (são parentes no grau de irmãos-completos). As estimativas foram relativamente altas e significativamente diferentes de zero $(0,414$ e 0,368$)$ antes e pós manejo. Os valores de $\hat{r}_{p(s)}$ foram significativamente diferentes de zero e levemente superiores a $\hat{r}_{p(m)}$, sugerindo que uma 
parte das progênies geradas por cruzamentos biparentais tinham árvores polinizadoras parentes entre si. Portanto, os cruzamentos não ocorreram de forma aleatória, o que explicaria as diferenças observada nas freqüências alélicas do pólen e dos óvulos. Alta correlação de paternidade também foi observada em outras espécies arbóreas tropicais de alta densidade populacional, igual a E. erythropappus. Gusson (2003) que encontrou valores de 0,577 $\pm 0,088$ em Eschweilera ovata e Seoane (2001) encontrou valores de 0,986 \pm 0,037 para Esenbeckia leiocarpa, ambas espécies arbóreas tropicais de alta densidade populacional.

A partir da correlação de paternidade, é possível estimar o número médio de indivíduos que efetivamente polinizaram as árvores maternas, ou seja, a média do número provável de indivíduos que contribuíram com pólen no evento de reprodução de uma árvore-mãe. As estimativas para a população foram baixas, em torno de dois a três polinizadores por árvore. Estudos semelhantes do sistema de reprodução, em espécies arbóreas tropicais, corroboram com este resultado. Alves et al. (2003), estudando uma população de Teobroma grandiflorum (Willd. \& Spreng.) Schum., encontraram que o número médio de polinizadores era de um a dois indivíduos. Moraes et al. (2004), estudando duas populações de Myracroduon urundeuva Fr. All. no sudeste do Brasil, detectaram de dois a três polinizadores efetivos. Resultados semelhantes também foram observados em Eucalyptus rameliana F. Muell (Sampson, 1998), Picea mariana (Mill.) BSP (Perry \& Bosquet (2001) e Grevillea iaspicula McGill (Hoebee \& Young, 2001). Estes resultados vêm de encontro com a teoria geral de que a polinização natural em espécies arbóreas era realizada a partir de grande número de plantas. Para Eschweilera ovata os valores foram de apenas uma dois em população uma natural e uma explorada, Gusson (2003).

É possível conhecer a proporção dos diferentes tipos de progênies na população, combinando-se a correlação de paternidade com a taxa de cruzamento multiloco. Para a população anterior ao manejo a proporção de irmãos-completos foi de $39,9 \%$, de meiosirmãos $56,4 \%$ e de irmãos de autofecundação 3,7\%. Já para a população posterior ao manejo, a proporção de irmãos-completos aumentou para $35,5 \%$, a de meios-irmãos foi de $61,1 \%$, não diferindo estatisticamente da taxa anterior ao manejo. A proporção de 
irmãos de autofecundação foi de 3,4\%, apresentando diminuição não significativa em relação à taxa da população anterior ao manejo. Portanto, aparentemente, o manejo não alterou o sistema de reprodução da espécie.

\subsubsection{Coeficiente de coancestria e tamanho efetivo de variância}

Os valores estimados para o coeficiente de coancestria dentro das progênies antes do manejo $(0,229)$ e posterior ao manejo $(0,222)$ foram superiores em $83,2 \%$ e $77,6 \%$ ao esperado em progênies de meios-irmãos $(0,125)$. O coeficiente de coancestria tem papel importante em programas de melhoramento e conservação genética, na estimativa do coeficiente de correlação de parentesco entre plantas dentro de progênies e tamanho efetivo de variância. Ele é a base do cálculo da variância genética aditiva e coeficiente de herdabilidade e ganho na seleção. Em espécies de cruzamentos, o coeficiente de correlação de parentesco é o dobro do coeficiente de coancestria, de forma que alterações na coancestria geram simultaneamente alterações no coeficiente de correlação de parentesco. Em progênies perfeitamente de meios-irmãos o coeficiente de parentesco estima 25\% da variação genética aditiva (Namkoong, 1966; Squillace, 1974; Ritland, 1989; Sebbenn et al., 2002). Assim, em caso da estimativa da variância genética aditiva, e parâmetros genéticos de caracteres quantitativos em progênies da presente populações de E. erythropappus, deveria-se usar os coeficiente de 0,458 e 0,444 , ao invés de 0,25, caso contrário as estimativas serão superestimadas. Portanto, assumindo-se progênies de meios-irmãos em programas de melhoramento para a espécie, corre-se o risco de superestimar a variância genética aditiva e outros parâmetros. Valores semelhantes para coeficiente de coancestria foram detectados para Trema micrantha e Cecropia pachystachya (0,247 e 0,235), (Kageyama et al., 2003).

O tamanho efetivo de variância mede a representatividade genética de uma população, em função de alterações nas freqüências alélicas entre gerações devido a efeitos de deriva genética no processo de reprodução. O sistema misto tem implicações na estimativa do tamanho efetivo de variância $\left(\hat{N}_{e(v)}\right)$, devido à endogamia causada por autofecundações e pelos cruzamentos entre aparentados, além da representatividade genética diminuir por causa da menor diversidade de polinizadores (menor número de 
plantas polinizadoras). Os valores estimados para este parâmetro foram de 1,99 e 2,08 para população antes do manejo e posterior ao manejo, respectivamente. Estes valores são basicamente a metade do valor teórico máximo esperado (aproximadamente 4) em uma simples progênie de uma população referencial ideal, ou seja, de tamanho infinito praticando cruzamentos aleatórios, sem seleção, mutação e migração. 
Tabela 8. Estimativa da divergência genética $\left(\hat{F}_{S T}\right)$ entre as freqüências alélicas do pólen e dos óvulos cruzados, freqüências alélicas nas árvores masculinas e femininas de uma população de Eremanthus erythropappus em Baependi - MG

\begin{tabular}{|c|c|c|c|c|c|c|c|c|c|c|c|c|c|}
\hline \multirow[b]{2}{*}{ Loco } & \multicolumn{7}{|c|}{ Antes do manejo } & \multicolumn{6}{|c|}{ Após o manejo } \\
\hline & Alelo & Pólen & Óvulo & $n$ & $\hat{F}_{S T}$ & $\chi^{2}$ & GL & Pólen & Óvulo & $n$ & $\hat{F}_{S T}$ & $\chi^{2}$ & GL \\
\hline \multirow[t]{3}{*}{ Acp } & 1 & 0,391 & 0,407 & & & & & 0,165 & 0,188 & & & & \\
\hline & 2 & 0,582 & 0,574 & & & & & 0,835 & 0,813 & & & & \\
\hline & 3 & 0,027 & 0,019 & 348 & $0,000 \mathrm{~ns}$ & 0,26 & 2 & 0 & 0 & 223 & $0,001 \mathrm{~ns}$ & 0,39 & 1 \\
\hline \multirow[t]{3}{*}{ Est } & 1 & 0,551 & 0,426 & & & & & 0,504 & 0,396 & & & & \\
\hline & 2 & 0,312 & 0,463 & & & & & 0,361 & 0,458 & & & & \\
\hline & 3 & 0,137 & 0,111 & 318 & $0,016^{* *}$ & 20,87 & 2 & 0,135 & 0,146 & 229 & $0,009 \mathrm{~ns}$ & 7,96 & 2 \\
\hline \multirow[t]{2}{*}{ 6pgdh } & 1 & 0,649 & 0,111 & & & & & 0,273 & 0,313 & & & & \\
\hline & 2 & 0,351 & 0,889 & 363 & $0,307^{* *}$ & 222,98 & 1 & 0,727 & 0,688 & 262 & $0,002 \mathrm{~ns}$ & 0,99 & 1 \\
\hline \multirow[t]{3}{*}{ G6pdh } & 1 & 0,991 & 0,907 & & & & & 0,906 & 0,854 & & & & \\
\hline & 2 & 0,009 & 0,093 & & & & & 0,059 & 0,104 & & & & \\
\hline & 3 & 0 & 0 & 385 & $0,036^{* *}$ & 28,06 & 1 & 0,035 & 0,042 & 277 & $0,005 \mathrm{~ns}$ & 6,09 & 2 \\
\hline \multirow[t]{3}{*}{ Pgm } & 1 & 0,627 & 0,481 & & & & & 0,648 & 0,417 & & & & \\
\hline & 2 & 0,367 & 0,519 & & & & & 0,333 & 0,583 & & & & \\
\hline & 3 & 0,006 & 0 & 179 & $0,022^{* *}$ & 16,02 & 2 & 0,019 & 0 & 108 & $0,057^{* *}$ & 24,78 & 2 \\
\hline \multirow[t]{3}{*}{ Pgi } & 1 & 0,961 & 0,778 & & & & & 0,485 & 0,813 & & & & \\
\hline & 2 & 0,039 & 0,222 & & & & & 0,506 & 0,146 & & & & \\
\hline & 3 & 0 & 0 & 346 & $0,074^{* *}$ & 51,06 & 1 & 0,009 & 0,042 & 250 & $0,126^{* *}$ & 126,24 & 2 \\
\hline \multirow[t]{2}{*}{ Dia } & 1 & 0,353 & 0,296 & & & & & 0,469 & 0,417 & & & & \\
\hline & 2 & 0,647 & 0,704 & 231 & $0,004 \mathrm{~ns}$ & 1,71 & 1 & 0,531 & 0,583 & 206 & $0,003 \mathrm{~ns}$ & 1,13 & 1 \\
\hline
\end{tabular}

***: $P<0,001$ 
Tabela 9. Estimativa de parâmetros demográficos, de endogamia, de sistema de reprodução e de fluxo gênico em população de Eremanthus erythropappus em Baependi - MG

\begin{tabular}{lcc}
\hline \multicolumn{1}{c}{ Parâmetro } & Antes & Após \\
\hline Número total de árvores matrizes $(m)$ & 27 & 24 \\
Número total de progênies $(n)$ & 405 & 289 \\
Índice de fixação na população adulta $(n=213): \hat{F}_{a}$ & $0,250 * *$ & --- \\
Índice de fixação nas árvores maternas: $\hat{F}_{m a t}$ & $-0,200$ & $-0,200$ \\
& $(0,041)$ & $(0,012)$ \\
Índice de fixação nas progênies: $\hat{F}_{p}$ & 0,112 & 0,005 \\
Taxa de cruzamento multiloco: $\hat{t}_{m}$ & 0,963 & 0,967 \\
Taxa de cruzamento uniloco: $\hat{t}_{s}$ & $(0,043)$ & $(0,043)$ \\
& 0,914 & 0,933 \\
Taxa de cruzamento entre parentes: $\hat{t}_{m}-\hat{t}_{s}$ & $(0,043)$ & $(0,043)$ \\
& 0,049 & 0,034 \\
Correlação de autofecundação: $\hat{r}_{s}$ & $(0,029)$ & $(0,029)$ \\
Correlação multiloco de paternidade: $\hat{r}_{p(m)}$ & 0,188 & 0,179 \\
Correlação uniloco de paternidade: $\hat{r}_{p(s)}$ & $(0,094)$ & $(0,094)$ \\
Cruzamentos envolvendo árvores polinizadoras & 0,394 & 0,357 \\
parentes: $\hat{r}_{s(s)}-\hat{r}_{p(m)}$ & $(0,069)$ & $(0,069)$ \\
Número médio de árvores polinizadoras: $1 / \hat{r}_{p(s)}$ & 0,414 & 0,368 \\
Proporção de irmãos-completos: $\hat{P}_{I C}=\hat{r}_{p} \hat{t}_{m}$ & $(0,077)$ & $(0,077)$ \\
Proporção de meios-irmãos: $\hat{P}_{M I}=\hat{t}_{m}\left(1-\hat{r}_{p}\right)$ & 0,020 & 0,010 \\
Proporção de irmãos de autofecundação: $\hat{P}_{I A}=1-\hat{t}_{m}$ & $(0,023)$ & $(0,023)$ \\
Coancestria média dentro de progênies: $\hat{\theta}_{x y}$ & 2,42 & 2,72 \\
Tamanho efetivo de variância: $\hat{N}_{e(v)}$ & 0,399 & 0,355 \\
Tamanho efetivo de variância total: $\hat{N}_{e(v) t}$ & 0,564 & 0,611 \\
Divergência genética do pólen cruzado entre matrizes: $\Phi$ & 0,037 & 0,034 \\
Número de árvores para reter o tamanho efetivo de $100(\hat{m})$ & 0,207 & 0,111 \\
$P<0,01,()=, 222$ \\
\end{tabular}
$P<0,01$, ( ) = número de indivíduos; $n=$ tamanho amostral, 


\subsection{Estrutura genética espacial}

Os resultados indicam forte estrutura genética espacial na população, com árvores próximas até aproximadamente $200 \mathrm{~m}$ apresentando algum grau de parentesco, com $95 \%$ de probabilidade, Figura 2. Até aproximadamente $75 \mathrm{~m}$ o parentesco entre árvores é próximo ao esperado entre indivíduos irmãos-completos $(0,25)$.

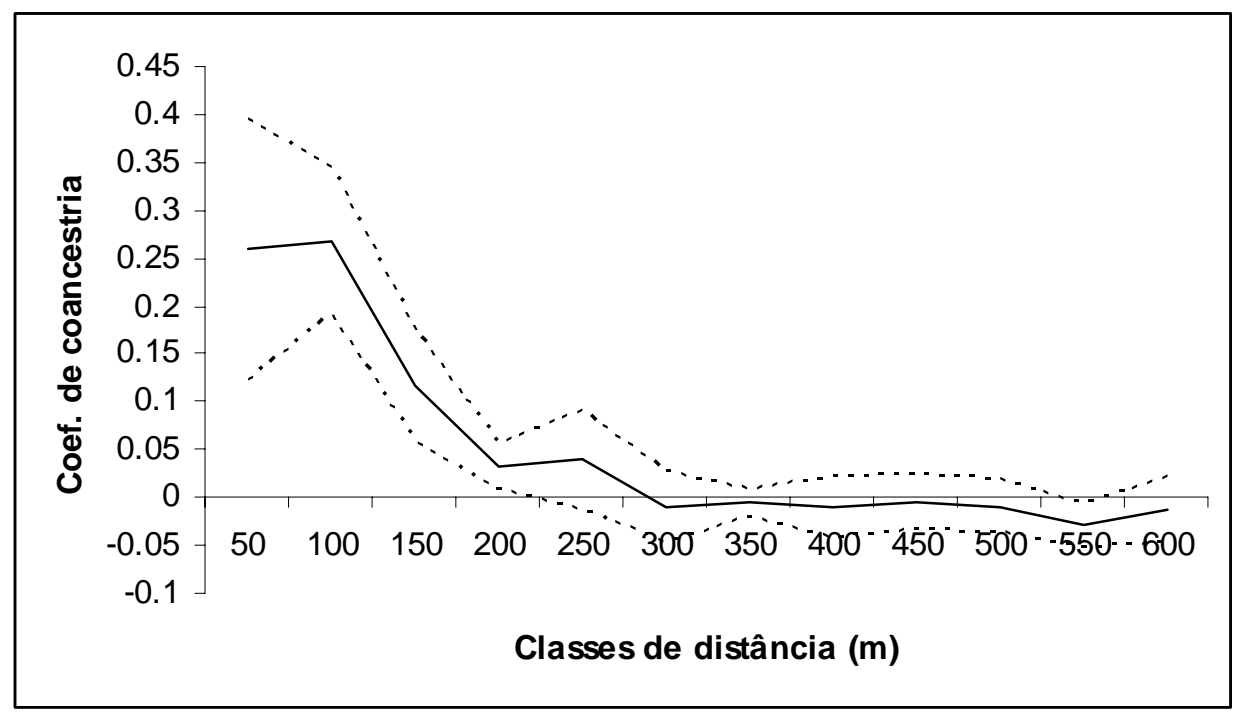

Figura 2- Classes de distância e coeficiente de coancestria para detecção de estrutura espacial de genótipos em população de Eremanthus erythropappus em Baependi - MG

As linhas tracejadas indicam o limite do intervalo de confiança a 95\% de probabilidade e a linha contínua representa a estimativa do coeficiente de coancestria.

Em espécies alógamas, a presença de autocorrelação pode ser atribuída muitas vezes à seleção ou à dispersão de sementes nas vizinhanças das matrizes. Linhart \& Grant (1996) explicam que o arranjamento espacial dos genótipos em estruturação de famílias pode ser causado por alguns fatores ecológicos, tal como a restrita dispersão do pólen e sementes. Estes autores comentam, ainda, que o fluxo gênico e a dispersão de sementes, contrariamente à sua natureza homogeneizadora, podem operar como uma fonte importante de heterogeneidade local em curtas distâncias. 
$\mathrm{Na}$ população de Eremanthus erythropappus estudada, pode-se observar que existe forte autocorrelação entre os indivíduos próximos, indicando estruturação em famílias.

Uma observação da área estudada é a marcante presença de regeneração da espécie de forma uniforme por toda a área. Não se pode inferir sobre o sucesso no estabelecimento destas plântulas mas, por tratar-ser de uma espécie comum, cerca de 400 indivíduos por ha, é provável que haja alta eficiência no estabelecimento. Assim, mesmo com processo de dispersão realizado pelo vento, o que nos leva a acreditar que as sementes sejam levadas a longas distâncias, a grande quantidade de sementes produzidas são depositadas nas vizinhanças da árvore materna e a facilidade de germinação em condições naturais aliadas a alta densidade natural da espécie, contradizem a idéia de que não deveria existir estruturação ou forte autocorrelação entre os indivíduos.

Assim como para a população de Eremanthus erythropappus, para Eschweilera ovata (Gusson, 2003), Symphonia globulifera (Degen et al, 2004) o mesmo padrão de distribuição espacial dos genótipos foi encontrado.

\subsection{Manejo e sustentabilidade}

Ainda que o manejo implementado na área de estudo não tenha tido a preocupação prévia com a sustentabilidade sob o ponto de vista genético, as análises dos parâmetros genéticos em diversidade e sistema de reprodução apresentaram-se até a presente geração em desacordo com as hipóteses iniciais deste trabalho.

Os alelos raros $(11 \%)$ e muito raros $(5 \%)$ estão presentes na população após o manejo nas mesmas proporções de antes do manejo o que não era esperado, ou seja, devido a alta diversidade da espécie na população estudada a retirada de indivíduos após o manejo poderia levar a diminuição da porcentagem destes alelos ou até mesmo ao desaparecimento destes na população caso o manejo fosse muito drástico.

Os maiores efeitos eram esperados no sistema de reprodução antes e após o manejo. No entanto não foi verificado aumento da taxa de autofecundação e na 
correlação de paternidade, aumento na proporção de irmãos completos, menor coeficiente de coancestria e menor tamanho efetivo de variância após o manejo.

A taxa de cruzamento multiloco foi alta e não houve diferença significativa na análise antes e após o manejo; no entanto, esta foi maior que a taxa uniloco indicando cruzamento entre aparentados. Este valor diminuiu e foi significativa a diferença após o manejo, sendo indicativo de que com o manejo houve a retirada de genótipos que elevavam esta taxa, e que poderia levar à endogamia a longo prazo.

Diferentemente do que se esperava, a taxa de cruzamentos biparentais antes do manejo foi estatisticamente igual à taxa após o manejo, indicando que o manejo não foi suficiente para que os cruzamentos biparentais fossem diminuídos pela retirada de genótipos. Tal fato pode ser devido ao evento da polinização que é executado por abelhas pequenas, com vôo curto e também pelo baixo número de indivíduos que contribuíram com pólen no evento de reprodução de uma árvore-mãe. As estimativas foram de 2 a 3 polinizadores por árvore, aumentando após o manejo.

A proporção de irmãos completos, também, ao contrário do que se esperava não aumentou significativamente e os coeficientes de coancestria, embora superiores aos esperados em progênies de meios-irmãos, não foram estatisticamente diferentes nas duas análises, indicando que o manejo novamente não afetou este parâmetro e devendo-se este valor às taxas de correlação de paternidade.

O tamanho efetivo de variância, por sua vez, também não foi afetado pelo manejo, já que as estimativas de 1,99 e 2,08 antes e após manejo, respectivamente, não são diferentes estatisticamente.

Além de efeitos drásticos do manejo não terem sido verificados em Eremanthus erythropappus, é necessário pesquisar a sustentabilidade deste ao longo das gerações. A regeneração da espécie é um aspecto essencial para a sustentabilidade do manejo. Neste caso, a espécie apresenta abundante regeneração e constitui-se como boa perspectiva à manutenção genética da população; no entanto, pode ser prejudicada caso o número de indivíduos reprodutivos retirados da área não sejam suficientes para impedir um efeito denominado de gargalo genético, que é basicamente a redução da população reprodutiva. 
Para tanto, é necessária a manutenção de porta sementes que venham a garantir a regeneração na área e que possam minimizar prováveis efeitos de deriva genética.

A determinação do número mínimo de porta-sementes a serem mantidos deve ser feito com base no tamanho efetivo da população da espécie. O tamanho efetivo de 50 tem sido sugerido como suficiente para manter o coeficiente de endogamia a uma taxa de $1 \%$ por geração, até 10 gerações, em locos com dois alelos, em populações de espécies com gerações discretas (Frankel \& Soulé, 1981).

Através das estimativas do tamanho efetivo de variância $\left(N_{e(v)}\right)$, foi possível estimar o número de matrizes necessárias para reter um $N_{e}$ igual a 50 para Eremanthus erythropappus. Este número foi de 51 e 49 matrizes para as populações anteriores e posteriores ao manejo, respectivamente. Assim, havendo interesse na conservação ex situ em curto prazo da espécie, aproximadamente 50 seria o número mínimo de árvores matrizes de uma população a ser considerado para a manutenção na área.

O tamanho efetivo de 50 tem sido preconizado para espécies que apresentam gerações discretas, sem sobreposição de gerações, o que não é o caso da $E$. erythropappus Assim, Sebbenn et al.(2001) sugeriram que este número seja ampliado para pelo menos 60. Tendo em vista que ocorrem aproximadamente 400 (veja texto anterior) indivíduos/ha, o que de acordo com a relação entre o tamanho efetivo de endogamia e o tamanho amostra $(0,75)$ indica que em cada hectare existe o tamanho efetivo de 300 , de forma que o tamanho efetivo de 60 por ha correspondem a apenas $20 \%$ do total de indivíduos. Em outras palavras, seria interessante que fossem mantidas aproximadamente 80 árvores por hectare. As plantas da população de E. erythropappus em questão devem estar em plena fase reprodutiva e distribuídas uniformemente por toda a área, a fim de otimizar os cruzamentos.

Tendo em vista os parâmetros de diversidade genética, deve-se negar as hipóteses iniciais de que o manejo poderá ser drástico para tal. A diversidade aumentou após o manejo e não diferiu estatisticamente dos valores esperados, indicando que o fato de o manejo ter diminuído os cruzamentos biparentais e cruzamentos entre parentes tenham elevado a diversidade observada na área. Lee et al. (2002) também não encontram diferenças na diversidade genética antes a após o manejo de Scaphium 
macropodum na Malásia. Contudo, seria interessante confirmar os resultados obtidos, avaliando os efeitos do manejo no longo prazo, usando modelagem e simulações. Também é importante averiguar se o diâmetro mínimo de corte, a intensidade de corte e tamanho do ciclo do corte garantem a sustentabilidade em termos de estoque de madeira.

Observou-se que a espécie apresenta agregação espacial dos genótipos sendo os indivíduos mais próximos aparentados entre si. O manejo seria então benéfico para reduzir a estruturação familiar com a retirada de indivíduos próximos com o objetivo de produção de madeira. Portanto, para que o manejo seja viável e adequado para a candeia, deve-se considerar não apenas a alta densidade da espécie, mas também a distribuição espacial dos genótipos e a manutenção de árvores porta-sementes (80).

Ressalta-se que os resultados encontrados neste estudo devem ser aplicados apenas a esta espécie na população estudada e que extrapolações para manejo de outras espécies não são aconselháveis, já que diferenças na densidade populacional, históricos de perturbação e características edafo-climáticas de ocorrência da espécie podem afetar direta ou indiretamente nos valores.

Como é de interesse de agricultores, a produção de mudas e plantio da espécie em escala comercial a coleta de sementes deve ser feita em árvores espaçadas em pelo menos $100 \mathrm{~m}$ a fim de se evitar a coleta em indivíduos aparentados entre si, um pouco além do já recomendado por Scolforo (2003). 


\section{CONCLUSÕES}

A reprodução na população de Eremanthus erythropappus estudada ocorre predominantemente por cruzamentos

A população da espécie apresenta altos níveis de diversidade genética, quando comparadas com outras espécies arbóreas tropicais.

As suas progênies apresentaram índice de fixação ideal para uma população panmítica.

Os parâmetros de diversidade genética antes a após o manejo apontam como possível o manejo sustentável para a espécie.

Para conservação ex situ em curto prazo da espécie, aproximadamente 50 seria o número mínimo de árvores matrizes de uma população a ser considerado para a manutenção na área. 


\section{REFERÊNCIAS BIBLIOGRÁFICAS}

ADAMS, W. T.; JOLY, R. J. Linkage relationships among twelve allozyme loci in loblolly pine. The Journal of Heredity, n. 71, p. 199-202, 1980.

ADRICH, P.R., HAMIRICK, J.L., CHAVARRIAGA, P.; KOCHERT, G. Microsatellite analysis of demographic genetic structure in fragmented populations of the tropical tree Symphonia globulifera. Molecular Ecology, n.7, p. 933-944, 1998.

ALFENAS, A. C.; PETERS, I.; BRUNE, W.; PASSADOR, G. C. Eletroforese de proteínas e fungos em essências florestais. Viçosa: UFV, 1991. 242p.

ALFENAS, S. A. (Ed.) Eletroforese de isoenzimas e proteínas afins: fundamentos e aplicações em plantas e microorganismos. Viçosa: UFV, 1998. 574p.

ALLARD, R.W. Princípios do melhoramento genético das plantas. Rio de Janeiro: USAID. Edgard Blucher, 1971. 381p.

ALVES, R. M. Caracterização genética de populações de cupuaçuzeiro, Theobroma grandiflorum (Willd. ex. Spreng.) Schum., por marcadores microssatélites e descritores botânico-agronômicos. Piracicaba, 2002.146p. Tese (Doutorado) - Centro de Energia Nuclear na Agricultura, Universidade de São Paulo.

ALVES, R. M.; ARTERO, A. S.; SEBBENN, A. M.; FIGUEIRA, A. Mating system in natural population of Theobroma grandiflorum (Willd ex Spreng) Shumm, Genetics and Molecular Biology, v. 26, n. 3, p. 373-379, 2003

ARAÚJO, L.C. Vanillosmopsis erythropappa (DC) Sch. Bip: sua exploração florestal. Rio de Janeiro: Escola Nacional de Agronomia, 1944. 58p.

BAWA, K. S. Breeding systems of tree species for a lowland tropical community. $\begin{array}{llllll}\text { Evolution, } & \text { v. } & 28, & \text { p. } & 85-92, & 1974 .\end{array}$ 
BAWA, K. S.; KRUGMAN, S. L. Reproductive biology and genetics of tropical trees in relation to conservation and management. In: GOMEZ-POMPA, A.; WHITMORE, T. C.; HADLEY, M. Rain forest regeneration and management. Paris: UNESCO, 1991. p. 119-136. (Man and the biosphere series, 6).

BERG, E. E.;HAMRICK, J. L. Quantification of diversity at allozyme loci. Canadian Journal Forest Research, v.27, p. 415-424, 1997.

BROWN, A. H. D. The role of isozyme studies in molecular systematics. Australian Systematics of Botany, v. 3, p. 39-46, 1990.

CÂNDIDO, J.F. Cultura de Candeia (Vanillosmopsis erythropappa Sch. Bip). n. 35, Viçosa: UFV, 1991. 7p. (Boletim de extensão).

CARVALHO, P. E. R. Espécies florestais brasileiras: recomendações silviculturais, potencialidades e uso da madeira. Colombo, EMBRAPA/CNPF, 1994. 640 p.

CAVALLARI NETO, M. Efeito do manejo na diversidade genética de populações naturais de Tabebuia cassinoides Lam (DC), por marcadores isoenzimáticos. Piracicaba, 2004. 67p. Dissertação (Mestrado) - Escola Superior de Agricultura “Luiz de Queiroz"- Universidade de São Paulo.

CENTRO TECNOLÓGICO DE MINAS GERAIS. Ecofisiologia da candeia. Belo Horizonte: SAT/CETEC, 1994. 104p. (Relatório Técnico).

CHAVES, M.M.F.; RAMALHO, R.S. Estudos morfológicos em sementes, plântulas e mudas de duas espécies arbóreas pioneiras da família Asteraceae (Vanillosmopsis erythrapappa Schult. Bip e Vernonia discolor (Spreng-Kess). Revista Árvore, v.20, n.1. p.1-7, 1996.

CHELIAK, W.M.; PITEL, J.A. Inheritance and linkage of allozymes in Larix laricina. Silvae Genetica, v. 34, p. 142-148, 1985.

CHUNG, M. G; EPPERSON, B. K. Spatial structure of allozyme polymorphism in a population of Eurya japonica. Silvae Genetica. v.49, n.1, p.1-4, 2000.

CLEGG, M. T. Measuring plant mating systems. Bioscience, v.30, n.12, p.814-818, 1980.

COCKERHAM, C.C. Variance of gene frequencies. Evolution, n. 23, p.72-84, 1969. 
COLES, J. F.; FOWLER, D. A Inbreeding in neighboring trees in two White Spruce population. Silvae Genetica, v. 25,n. 1, p.29-34, 1976.

CORREAA, M.P. Dicionário de plantas úteis do Brasil. Rio de Janeiro: Ministério da Agricultura, 1931. v. 1. p. 431-433.

DEGEN, B.; BANDOU, E.; CARON, H. Limited pollen dispersal and biparental inbreeding in Symphonia globulifera in French Guiana. Heredity, n.93, p. 585-591, 2004

FRANKEL, O. H.; SOULÉ, M. S. Conservation and evolution. Cambridge: Cambridge University Press, 1981. 327p.

FUTUYMA, D.J. Biologia evolutiva. Ribeirão Preto: SBG, 1992.646p.

GANDARA, F. B. Diversidade genética, taxa de cruzamento e estrutura espacial dos genótipos em uma população de Cedrela fissilis Vell. (Meliaceae). Piracicaba, 1996. 69p. Dissertação (Mestrado) - Escola Superior de Agricultura "Luiz de Queiroz”, Universidade de São Paulo.

GILLET, E.; HATTEMER, H.H. Genetic analysis of isoenzyme phenotypes using single tree progenies. Heredity, v. 63, p. 135-141, 1989.

GLAUBITZ, J. C.; MORAN, G.F. Genetic tools: the use of biochemical and molecular markers. In: YOUNG, A. ; BOSHIER, D.; BOYLE, T. (Ed.) Forest Conservation genetics: principles and practice. Collingwood: CSIRO, 2000. p.39-59.

GUSSON, E. Uso e diversidade genética em populações naturais de Biriba (Eschweilera ovata [Cambess.] Miers): subsídios ao manejo e conservação da espécie. Piracicaba, 2003. 91p. Dissertação (Mestrado) - Escola Superior de Agricultura "Luiz de Queiroz”, Universidade de São Paulo.

HAMRICK, J. L. The distribuition of genetic variation within and among natural plant population. In: SCHONE-WALD-COX, C. M.; CHAMBERS, S. H.; MacBYDE, B.; THOMAS, L. Genetics and conservation. Menlo Park: Benjamin Cummings, 1983, p. 335-348.

HAMRICK, J. L. Isozymes and analyses of genetic structure of plant populations. In: SOLTIS, D.; SOLTIS, P. (Ed.). Isozymes in plant biology, Portland Oregon: Discorides Press, 1989. p.87-105. 
HAMRICK, J. L.; LOVELESS, M. D. The influence of seed dispersal mechanisms on the genetic structure of plant populations. In: ESTRADA, A.; FLEMING, T. H. (Ed.) Frugivores and seed dispersal. Athens: junk Publishers, 1986. cap. 17, p. $124-145$.

HAMRICK, J. L.; GODT, M. J. Allozyme diversity in plant species In: BROWN, A. H. D.; CleGG, A. L.; KAHLER; WEIR, B. S. ( Ed.) Plant population genetics breeding and germplasm resources, Sunderland, Mass: Sinauer, 1989, p.43-63.

HAMRICK, J. L.; LOVELESS, M. D. The Genetic Structure of Tropical Tree Populations: Associations With Reproductive Biology. In: LINHART, Y. B. (Ed.) Plant evolutionary ecology, Westview Press, Boulder. 1989, p. 129-146.

HAMRICK, J. L.; GODT, M. J. Allozyme diversity in plant species In: BROWN, A. H. D.; CLEGG, M. T.; KAHLER, A. L.; WEIR, B. S. (Ed.) Plant population genetics, breeding and germplasm resources. Sunderland, Mass: Sinauer, 1990. p. 43-63.

HAMRICK, J. L.; LINHEART, Y. B.; MITTON, J. B. Relationships between life history characteristics and eletrophoretically detectable genetic variation in plants. Annual Review of Ecology and Systematics, v.10, p.173-200, 1979.

HARDY. O.; VEKEMANS. X. SPAGeDI 1.1. A program for spatial pattern analysis of genetic diversity. Version for Windows 95. 2003.

HOEBEE, S. E.; YOUNG, A. G. Low neighbourhood size and hig interpopulation differentiation in the endangered shrub Gervillea iaspicula. Heredity, v. 88, p. 489496, 2001.

HUANG, Q.Q.; TOMARU, N.; WANG, L.H.; OHBA, K. Genetic control of isozyme variation in Masson Pine, Pinus massoniana Lamb. Silvae Genetica, v. 43, p. 285292, 1994.

KAGEYAMA, P. Y. Uso e conservação de florestas tropicais: qual paradigma? In: SIMPÓSIO DE ECOSSISTEMAS BRASILEIROS: Conservação, 5., Vitória - ES, 2000. Anais São Paulo: ACIESP, 2000. p. 72-82. 
KAGEYAMA, P.Y.; GANDARA, F. B.; VENCOVSKY, R. Conservação in situ de espécies arbóreas nativas. ln: NAS, L. L.; VALOIS, A. C. C.; IVELO, I. S.; VALADARES-INGLIS, M. C. Recursos genéticos e melhoramento. Rondonópolis: Fundação MT, 2001. p. 149-159.

KAGEYAMA, P. Y.; LEPSCH-CUNHA, N. M. Singularidade da biodiversidade nos trópicos. In: GARAY, I.; DIAS, B. F. S. (Ed.). Conservação da biodiversidade em ecossistemas tropicais, Petrópolis: Editora Vozes, 2001. p. 199-214.

KAGEYAMA, P. Y.; SEBBENN, A. M.; RIBAS, L. A.; GANDARA, F. B.; CASTELLEN, M.; PERECIM, M. B.; VENCOVSKY, R. Diversidade genética em espécies arbóreas tropicais de diferentes estágios sucessionais por marcadores genéticos. Scientia Forestalis, n. 64, p. 93-107, dez.2003.

KAWAGUICI,C. B. Variação genética em três grupos de indivíduos (adultos, jovens e plântulas) de Calophyllun brasiliense Camb. (Clusiaceae), em Mata de Galeria. Piracicaba, 1999. 98p. Dissertação (Mestrado) - Escola Superior de Agricultura “Luiz de Queiroz"- Universidade de São Paulo.

KONNERT, M.; RUETZ, W.; FROMM, M. Genetic variation in Acer pseudoplatanus L. I. Inheritance of isozymes variants. Forest Genetics, v. 8, p. 25-37, 2001.

KRICHER, J.C.A. Neotropical companion: an introduction to animals, plants and ecosystems of the new world tropics. New Jersey: Princeton University Press., 1990. 435p.

LEPSCH-CUNHA, N. Estrutura genética e fenologia de espécies raras de Couratari spp. na Amazônia Central. Piracicaba, 1996, 147p. Dissertação (Mestrado) - Escola Superior de Agricultura “Luiz de Queiroz”, Universidade de São Paulo.

LEDIG, F.T. Heterozygosity, heterosis, and fitness in outbreeding plants. In: SOULÉ, M. (Ed.). Conservation biology, Cambridge Blackwell Science, Sinauer Associates. 1986. p.77-104.

LEDIG, F. T. Human impacts on genetic diversity in forest ecosystems. Oikos, v. 63, p. 87-108, 1992. 
LEE, C. T.; WICKNESWARI, R.; MAHANI, M. C.; ZAKRI, A. H. Effect of selective logging on the genetic diversity of Scaphium macropodum. Biological Conservation, n. 104, p. 107-118, 2002.

LEWIS, P.0.; ZAYKIN, D. GDA - Genetic date analysis: Version 1.0(d12) for Windows. Albuquerque: The University of New Mexico, 1999. p. 131-1051.

LINHART, Y.B.; MITTON, J.B.; STURGEON, K.B.; DAVIS, M.L. Genetic variation in space and time in a population of ponderosa pine. Heredity, v. 46, p. 407-426, 1981

LOISELLE, B. A.; SORK, V.L.; NASON, J.; GRAHAM, C. Spatial genetic structure of a tropical understory shrub, Psychotria officinalis (Rubiaceae). American Journal of Botany, v. 82, n. 11, p. 1420-1425, 1995.

LOVELESS, M. D.; HAMRICK, J. L. Ecological determinants of genetic structure in plant populations. Annual Review of Ecology and Systematics, v. 15, p. 65-95, 1984.

LOVELESS, M.D.; HAMRICK, J.L. Distribuicion de la variacion en espécies de arboles tropicales. Revista Biologia Tropicales, v.35, n.1, p. 165-75, 1987.

MACLEISH, N.F.F. Revision of Eremanthus (Compositae: Vernoniaceae). Annals Missouri Botanical Garden, v.74, p.265-290, 1987.

MALTEZ, H. M. Estutura genética de Aspidosperma polyneuron Muell. Arg. Apocynaceae em uma floresta estacional semidecidual no Estado de São Paulo. 1997, 132p. Dissertação (Mestrado) - Universidade de Campinas.

MITTON, J.B. Conifers. In: TANKSLEY, S.D.; ORTON, T.J. (Ed.). Isozymes in plant breeding and genetics, Amsterdam: Elservier Sci. Publ., 1983. p. 443-472.

MORAES, M. L. T. de Variabilidade genética por isoenzimas e caracteres quantitativos em duas populações naturais de aroeira Myracroduon urundeuva F. F. \& M. F. Allemão - Anacardiaceae (Syn: Astronium urundeuva (Fr. Allemão) Enger). Piracicaba, 1993. 139p. Tese (Doutorado) - Escola Superior de Agricultura "Luiz de Queiroz”, Universidade de São Paulo. 
MORAES, M.L.T.; KAGEYAMA, P.Y.; SEBBENN, A.M. Correlated mating in dioecious tropical tree species, Myracrodruon urundeuva Fr. All. Forest Genetics, v. 11, n. 1, p. 53-59, 2004.

MORGANTE, M.; VENDRAMIN, G. G.; GIANNINI, R. Inheritance and linkage relationships of isozyme variants of Pinus leucodermis. Silvae Genetica, v.42, n.4/5, p.231-237, 1993.

MURAWSKI, D. A. Reproductive biology and genetics of tropical trees from canopy perspective. In: LOWMAN,M. D.; NADKARNI, N. M. (Ed.). Forest canopies. New York: Academic Press, 1995. p. 457-493.

MURAWSKI, D. A.; BAWA, K. S. Genetic structure and mating system of Stemonoporus oblongifolius (Dipterocarpaceae) in Sri Lanka. American Journal of Botany, v.81, n.2, p.155-160, 1994.

MURAWSKI, D. A.; HAMRICK, J.L.; HUBBELL,S. P.; FOSTER, R.B. Mating system of two Bombacaceous trees of a neotropical moist forest. Oecologia, v.82, p.501506,1990 .

MYERS, N. Threatened biotas: Hotspots in tropical forests. Environmentalist, v.8, p.120, 1988.

NAMKOONG, G. Inbreed effects on estimation of genetic additive variance. Forest Science, v. 12, p. 8-13, 1966.

OBAYASHI, K.; TSUMARA, Y.; IHARA-UNINO, T.; NIIYAMA, K.; TANOUCHI, H.; SYYAMA, Y.; WASHITANI, I., LEE, C.; LEE, S.L.; MUHAMMAD, N.Genetic diversity and outcrossing rate between undisturbed and selective logged forest of Shorea curtissi using microsatellite DNA analysis. International Journal of Plant Science, v. 163, n. 1, p.151-158, 2002.

O'MALLEY, D. M.; BAWA, K. S. Mating system of a tropical rain forest tree species, American Journal of Botany, v.74, p. 1143-1149, 1987.

PEDRALLI, G. Estrutura diamétrica, vertical e análise do crescimento da candeia (Vanillosmopsis erythropappa Schult. Bip) na Estação Ecológica do Tripuí, Ouro Preto, MG. Revista Árvore, v. 21, n. 2, p. 301-306, abr.jun. 1996. 
PEDRALLI, G.; TEIXEIRA, M. C. B.; NUNES, Y. R. Estudos sinecológicos sobre a candeia (Vanillosmopsis erythropappa Schult. Bip) na Estação Ecológica de Tripuí, Ouro Preto (MG, Brasil). FOREST, p.117-118. abr.jun. 1996.

PEREIRA, V.A. A. C. Diversidade genética de Miconia cinnamomifolia (D.C.) Naudim em áreas sob interferência antrópica na Mata Atlântica. Piracicaba, 2002, 84p. Dissertação (Mestrado) - Escola Superior de Agricultura "Luiz de Queiroz", Universidade de São Paulo.

PERRY, D. J.; BOUSQUET, J. Genetic diversity and mating system of post-fire and post-harvest black spruce: an investigation using codominant sequence-tagged-site markers. Canadian Journal Forest research, v. 31, p. 32-40, 2001.

POTENKO, V. Inheritance of allozymes and genetic variation in natural population of Japanese Yew in Petrov Island, Russia. Forest Genetics, v. 8, p, 307-313, 2001.

REIS, M. S. Distribuição e dinâmica da variabilidade genética em populações naturais de palmiteiro (Euterpe edulis Martius). Piracicaba, 1996. 203p. Tese (Doutorado) Escola Superior de Agricultura “Luiz de Queiroz”, Universidade de São Paulo.

RIBAS, L. A. Diversidade genética e sistema de cruzamento em populações naturais de duas espécies pioneiras arbóreas. Piracicaba, 2003. 103p. Tese (Doutorado)- Escola Superior de Agricultura “Luiz de Queiroz”, Universidade de São Paulo.

RITLAND, K. Correlated matings in the partial selfer Mimulus guttatus. Evolution, v.43, n.4, p.848-859, 1989.

RITLAND, K. Series of FORTRAN Computer programs for estimating plant mating systems. Journal of Heredity, v. 81, p. 235-237,1990.

RITLAND, K. Extensions of models for the estimation of mating systems using $n$ independent loci. Heredity, v. 88, p. 221-228, 2002.

RITLAND, K.; JAIN, S. A model for the estimation of outcrossing rate and gene frequencies using independent loci. Heredity, v.47, p.35-52, 1981.

SAMPSON, J. F. Multiple paternity in Eucalyptus rameliana (Myrtaceae). Heredity, v.81, p. 349-355, 1998. 
SANTOS, E. M. G. Ecologia da polinização, fluxo de pólen e taxa de cruzamento em Bauhinia forficata Link. (Caesalpinaceae). Piracicaba, 1994. 114p. Dissertação (Mestrado) - Escola Superior de Agricultura "Luiz de Queiroz", Universidade de São Paulo.

SANTOS, J. D. Estudos ecológicos e genéticos em uma paisagem fragmentada no Pontal do Paranapanema - São Paulo. Piracicaba, 2002. 100p. Dissertação (Mestrado) - Escola Superior de Agricultura "Luiz de Queiroz" - Universidade de São Paulo.

SCOLFORO, J. R.; OLIVEIRA, A. D.; DAVIDE, A. C.; CAMOLESI, J. F. Manejo sustentado das candeias Eremanthus erythropappus (DC.) McLeish e Eremanthus incanus (Less.) Less. 2003. 62p.

SEBBENN, A. M. Estrutura genética de subpopulações de Genipa americana L. (Rubiaceae) a partir de isoenzimas. 1997, 107p. Dissertação (Mestrado) - Escola Superior de Agricultura “Luiz de Queiroz”, Universidade de São Paulo.

SEBBENN, A. M. Amostragem para estimativa de freqüências alélicas e índices de diversidade genética em espécies florestais. Revista do Instituto Florestal, v.14, n.1, p. 27-38, 2002.

SEBBENN, A.M. Herança e ligação em locos de isoenzimas em Genipa americana L. Revista do Instituto Florestal, v. 16, n. 1, p. 65-72, 2004.

SEBBENN, A. M.; KAGEYAMA, P. Y.; VENCOVSKY, R. Variabilidade genética, sistema reprodutivo e estrutura genética espacial em Genipa americana L. através de marcadores isoenzimáticos. Scientia Forestalis. n. 53, p. 15-30, jun. 1998.

SEBBENN, A.M.; KAGEYAMA, P.Y.; ZANATTO, A.C.S. Estimativas de ganhos genéticos na seleção em populações de Cariniana legalis (Mart.) O. Ktze, incorporando informações do sistema misto de reprodução. Revista do Instituto Florestal. v 14, n. 1, p. 65-77. 2002.

SEBBENN, A. M.; SEOANE, C. E. S.; KAGEYAMA, P. Y. Efeitos do manejo na estrutura genética de populações de caixeta (Tabebuia cassinoides) Scientia Forestalis. n. 58, p. 127-143, dez. 2000. 
SEBBENN, A.M.; SEOANE, C. E. S.; KAGEYAMA, P. Y.; LACERDA, C.M.B. estrutura genética em populações de Tabebuia cassinoides: Implicações para o manejo florestal e a conservação genética. Revista do Instituto Florestal, v.13, n.2, p.93-113, 2001.

SEOANE, C.E.C.; SEBBENN, A.M.; KAGEYAMA, P.Y. Sistema reprodutivo em populações de Esenbeckia leiocarpa, Revista do Instituto Florestal, v. 13, n. 1, p 19-26, 2001

SHIRAISHI, S. Inheritance of isozymes variation in Japanese Black Pine, Pinus thunbergii Parl. Silvae Genetica, v. 37, p. 93-100, 1988.

SOKAL, R. R.; ROHLF, F. J. Biometry. New York: W. H. Freeman,1981. 859 p.

SOLTIS, D. E.; SOLTIS, P. S. Isozyme in plant biology. Portland, Oregon: Discorides Press, 1989. 268p. (Advances in plant science, 4).

SOUSA, V.A.; HATTEMER, H.H.; ROBINSON, I.P. Inheritance and linkage relationships of isozyme variants of Araucaria angustifolia (Bert.) O. Ktze. Silvae Genetica, v. 51, p. 191-196, 2002.

SOUZA, L.M.F.I.; KAGEYAMA, P. Y.; SEBBENN, A. M. Sistema de reprodução em população natural de Chorisia speciosa . Revista Brasileira de Botânica, v. 26, n.1, p.113-121, 2003.

SQUILLACE, A. E. Average genetic correlations among offspring from open-pollinated forest trees. Silvae Genetica, v. 23, p. 149-156, 1974.

STEBBINS, G.L. Introduction. In: SOLTIS, D.E.; SOLTIS, P.S. (Ed.). Isozymes in plant biology. Portland, Oregon: Discorides Press, 1989. 268p. (Advances in plant science, 4).

STRAUSS, S.H.; CONKLE, M.T. Segregation, linkage and diversity of allozymes in knobcone pine. Theoretical Applied Genetic, v. 72, p. 483-493, 1986.

SWOFFORD, D. L.; SELANDER, R. B. Byosis-1. A computer program analysis of allelic variation in population genetics and biochemical systematics. Release 1, 7. David I. Swofford. Illinois: Natural History Survel All Rights Reserved. 1989. 43p. 
TEIXEIRA, MCB.; NUNES, YRF.; MAIA, KMP ; RIBEIRO, R.N. Influência da luz na Germinação de sementes de candeia (Vanillosmopsis erythropappa Schult. Bit). In: XVIII-ERBOT. Anais Pontifícia Universidade Católica de MG. 1996. p. 23-24.

WEIR, B.S. Inferences about linkage disequilibrium. Biometrics, v. 35, p. 235-354, 1979.

WEIR, B. S. Genetic data analysis II. Methods for discrete population genetic data. Suderland: Sinauer, 1996. 445p.

WEIR, B.S.; COCKERHAM, C.C. Estimation of linkage disequilibrium in randomly mating populations. Heredity, v. 43, p. 105-111, 1979.

WEIR, B. S.; COCKERHAM, C. C. Estimating F-statistics for the analysis of population structure. Evolution, v.38, p.1358-1370, 1984.

WHITE, G.M.; BOSHIER, D.H.; POWELL, W. Increased pollen flow counteracts fragmentation in tropical dry Forest: an example from Swietenia humilis Zuccarini. PNAS, v. 99, p. 2038-2042, 2002.

WORKMAN, P.; NISWANDER, J. L. Populations studies on southwestern Indian Tribes. II. Local genetic differentiation in the Papago. American Journal Human Genetic, v.22, p. 24-29, 1970.

WRIGHT, S. The interpretation of population structure by F-statistics with special regard to systems of mating. Evolution, v. 19, p. 395-420, 1965.

WRIGHT, S. Evolution and the genetics of populations. Variability within and among natural populations. Chicago: University of Chicago Press, v.4, 1978. 423p.

YEH, F.C.; YANG, R.; BOYLE, T. POPGENE version 1.32: Microsoft Window-based freeware for Population genetics analysis. University of Alberta, Edmonton, Canada. 1999. (30 Mar. 2004).

YOUNG, A.; BOYLE, T.; BROWN,T. The population genetic consequences of habitat fragmentation for plant. Tree, v.11, n.10, p. 100-106, 1996. 